\title{
Co-Regulation of Transcellular and Paracellular Leak Across Microvascular Endothelium by Dynamin
} and Rac

\author{
Susan M. Armstrong, ${ }^{*}$ Vahid Khajoee, ${ }^{\dagger}$ \\ Changsen Wang, ${ }^{\dagger}$ Tieling Wang, ${ }^{\dagger}$ Jayesh Tigdi, ${ }^{\dagger}$ \\ Jun Yin, ${ }^{\dagger}$ Wolfgang M. Kuebler, ${ }^{\dagger}$ Mark Gillrie, ${ }^{\ddagger}$ \\ Shevaun P. Davis, ${ }^{\ddagger}$ May Ho, ${ }^{\ddagger}$ and \\ Warren L. Lee ${ }^{\star \dagger \S}$ \\ From the Institute of Medical Science ${ }^{*}$ and the Division of \\ Respirology and Interdepartmental Division of Critical Care \\ Medicine, ${ }^{\Im}$ Faculty of Medicine, University of Toronto, Toronto, \\ Ontario; the Keenan Research Centre of the Li Ka Shing \\ Knowledge Institute, ${ }^{\dagger}$ St. Michael's Hospital, Toronto, Ontario; \\ and the Departments of Microbiology and Infectious Diseases \\ and Medicine, ${ }^{\ddagger}$ University of Calgary, Calgary, Alberta, Canada
}

Increased permeability of the microvascular endothelium to fluids and proteins is the hallmark of inflammatory conditions such as sepsis. Leakage can occur between (paracellular) or through (transcytosis) endothelial cells, yet little is known about whether these pathways are linked. Understanding the regulation of microvascular permeability is essential for the identification of novel therapies to combat inflammation. We investigated whether transcytosis and paracellular leakage are co-regulated. Using molecular and pharmacologic approaches, we inhibited transcytosis of albumin in primary human microvascular endothelium and measured paracellular permeability. Blockade of transcytosis induced a rapid increase in paracellular leakage that was not explained by decreases in caveolin-1 or increases in activity of nitric oxide synthase. The effect required caveolin- 1 but was observed in cells depleted of clathrin, indicating that it was not due to the general inhibition of endocytosis. Inhibiting transcytosis by dynamin blockade increased paracellular leakage concomitantly with the loss of cortical actin from the plasma membrane and the displacement of active Rac from the plasmalemma. Importantly, inhibition of paracellular leakage by sphingosine-1-phosphate, which activates Rac and induces cortical actin, caused a significant increase in transcytosis of albumin in vitro and in an ex vivo whole-lung model. In addition, dominant-negative Rac significantly diminished albumin uptake by endothe- lia. Our findings indicate that transcytosis and paracellular permeability are co-regulated through a signaling pathway linking dynamin, Rac, and actin. (Am J Pathol 2012, 180: 1308-1323; DOI: 10.1016/j.ajpath.2011.12.002)

One of the critical functions of the endothelium is the maintenance of an intact barrier between the vascular lumen and the interstitium. Numerous inflammatory diseases, including acute lung injury, sepsis, and anaphylaxis, are characterized by prolonged and excessive microvascular leak. ${ }^{1-3}$ In such settings, the exodus of proteins and fluids has deleterious consequences, ${ }^{4,5}$ including the loss of serum albumin and oncotic pressure ${ }^{6}$ and culminating in the development of hypotension and tissue edema. There is great interest, therefore, in developing novel agents that decrease microvascular leak. However, for this to be successful, understanding the mechanisms and regulation of microvascular permeability is essential. ${ }^{3}$

Inflammatory mediators can induce vascular leak by opening gaps in endothelial cells, a process known as paracellular leak. ${ }^{7-9}$ Although the mechanisms of gap formation depend in part on the inflammatory stimulus, they can be broadly divided into three overlapping

Supported by the Canadian Institutes of Health Research (CIHR), Keenan Research Centre of the Li Ka Shing Knowledge Institute of St. Michael's Hospital. S.M.A. is supported by an MD/PhD Studentship award from the $\mathrm{CIHR}$ and an MD/PhD Studentship award from the McLaughlin Centre. W.L. is supported by a Clinician Scientist Phase II Award from the Canadian Institutes of Health Research and by the Keenan Research Centre of the Li Ka Shing Knowledge Institute of St. Michael's Hospital.

Accepted for publication December 2, 2011

Portions of this work were presented at the 16th International Vascular Biology Meeting (June 20-24, 2010, Los Angeles, CA)

Supplemental material for this article can be found at http://ajp. amjpathol.org or at doi: 10.1016/j.ajpath.2011.12.002.

Current affiliation of V.K., Hospital for Sick Children, Toronto, Ontario, Canada

Address reprint requests to Warren L. Lee, M.D., Ph.D., St. Michael's Hospital, 30 Bond Street, LKS Room 613, Toronto, ON, Canada M5B 1W8. E-mail: warren.lee@utoronto.ca. 
categories: i) injury and/or apoptosis of cells in the endothelial monolayer, ${ }^{10,11}$ ii) internalization or disassembly of intercellular junctions, ${ }^{12,13}$ and iii) remodeling of the actin cytoskeleton, leading to a change in cell shape. Cytoskeletal remodeling is regulated by members of the Rho GTPase family, which recruit downstream effectors when bound to GTP. For instance, the formation of the cortical actin fibers that normally buttress the plasmalemma is dependent on Rac, ${ }^{14,15}$ whereas the generation and contraction of cytoplasmic actinomyosin stress fibers require RhoA. ${ }^{16,17}$

Although paracellular leak is more widely studied, leakage of plasma and proteins can also occur through the cytoplasm of endothelial cells by transcytosis. ${ }^{18,19}$ In fact, transcytosis is a physiologically important process that accounts for much of albumin transit across the resting endothelium. ${ }^{20}$ This involves the traffic of caveolae, small intracellular vesicles that are often docked to the plasmalemma, and begins with binding of albumin by multiple receptors on the apical endothelial surface. ${ }^{19,21,22}$ This leads to the invagination of caveolae from the plasma membrane. The GTPase dynamin- $2^{23}$ forms a ring around the neck of the invaginating vesicles and mediates their scission from the plasmalemma. ${ }^{24}$ The vesicles then move into the cell, fuse with the basolateral membrane, and release albumin to the interstitial space. Accordingly, caveolae contain SNARE proteins and the hexameric ATPase $\mathrm{N}$-ethylmaleimide (NEM)sensitive factor, both of which are required for the fusion of vesicles to the plasmalemma. ${ }^{19}$ In contrast to paracellular leak, nothing is known about the relationship between Rac and RhoA and transcytosis. In addition to albumin, transcytosis occurs for immunoglobulins, transferrin, aminopeptidase $\mathrm{P},{ }^{25}$ and numerous other molecules. ${ }^{18}$

Although both paracellular and transcellular leak were described decades ago, remarkably little is known about the relationship between them. Endothelial cells from mice deficient in caveolin-1 lack caveolae and do not perform transcytosis. ${ }^{26}$ The vasculature from these animals demonstrates an increase in permeability, although the mechanism of this change is controversial. Although some have described a compensatory induction of paracellular leak, ${ }^{26}$ others attribute the effect to a change in capillary pressure or the endothelial glycocalyx. ${ }^{27}$ Furthermore, caveolin-1 has numerous functions in cell signaling and growth, ${ }^{28}$ making it impossible to know whether the increase in permeability is due to the loss of transcytosis per se or to the loss of caveolin-1. Thus, how paracellular and transcellular leak are related remains largely unexplored. We hypothesized that, independent of caveolin-1, inhibition of transcytosis would lead to a compensatory increase in paracellular leak. To address this issue, we first devised methods of measuring transcytosis of albumin by primary human microvascular endothelium in culture. We then inhibited transcytosis by multiple distinct molecular and pharmacologic approaches and determined the effect on paracellular leak. Reciprocally, we inhibited paracellular leak and monitored for changes in transcytosis both in vitro and using an ex vivo lung model. Lastly, we determined the molecular mechanism for this relationship.

\section{Materials and Methods}

\section{Cell Culture}

Primary human microvascular endothelial cells of dermal origin were obtained from discarded human foreskin as previously described ${ }^{29}$ and were used throughout the study. Primary human microvascular endothelial cells of pulmonary origin were obtained from Lonza (Basel, Switzerland) and were used to confirm the results of key transwell experiments, as indicated below. Cells were cultured in EBM-2 media with the recommended supplements (Lonza) and were used in passages 3 to 8 .

\section{Transwell Assays}

Endothelial cells were seeded on gelatin-coated 0.4- $\mu \mathrm{m}$ pore polyester transwells (Costar, Corning, NY) and grown until confluency 1 to 3 days later. Only monolayers that appeared healthy by phase-contrast microscopy and had a transendothelial electrical resistance (TEER; measured using Endohm-12 from World Precision Instruments, Sarasota, FL) of $>19 \Omega \mathrm{cm}^{2}$ were used for permeability experiments. Replacement of the TEER machine led to higher TEER values in some experiments, but permeability to dextran remained unchanged.

To measure transcytosis, endothelial monolayers were allowed to bind but not internalize fluorescein isothiocyanate (FITC)-conjugated albumin (Invitrogen, Eugene, OR; $0.4 \mathrm{mg} / \mathrm{mL}$ ) for 10 minutes at $4^{\circ} \mathrm{C}$. Unbound albumin was removed by washing the cells with cold media twice. Transcytosis was allowed to proceed by incubating the cells at $37^{\circ} \mathrm{C}$ for 2 hours. As controls, $80 \mu \mathrm{mol} / \mathrm{L}$ Dynasore (Sigma-Aldrich, St Louis, MO) or $4 \mathrm{mmol} / \mathrm{L}$ histamine (Sigma-Aldrich) were added for the incubations at $37^{\circ} \mathrm{C}$. Aliquots of the lower and upper chambers were then taken and measured for fluorescence in a Spectramax Gemini EM (Molecular Devices, Sunnyvale, CA) using the appropriate filter sets and after subtraction of appropriate blanks.

To measure transcytosis by a second method, serum-free media containing $0.3 \mathrm{mg} / \mathrm{mL}$ of biotin-tagged albumin (biotin-BSA; Thermo Scientific, Rockford, IL) and $50 \mu \mathrm{g} / \mathrm{mL}$ of FITC-conjugated dextran (Invitrogen; molecular weight, $70 \mathrm{kDa}$ ) were added to the upper chamber of the transwell, whereas serum-free media alone was added to the lower chamber. After 4 hours of incubation, aliquots from the lower chamber were taken for measurement of biotin-BSA by enzyme-linked immunosorbent assay (ELISA) (see below). As a control for paracellular leak, aliquots were also taken for measurement of FITC-dextran fluorescence intensity in a Spectramax Gemini EM (Molecular Devices) using the appropriate filter sets and after subtraction of appropriate blanks.

For the ELISA, $100 \mu \mathrm{L}$ of media from the lower chamber and $50 \mu \mathrm{L}$ of $0.5 \mu \mathrm{g} / \mathrm{mL}$ of horseradish peroxidase- 
conjugated sheep anti-BSA (Immunology Consultants Laboratory, Inc., Newberg, OR) were incubated in 96well plates coated with streptavidin (Thermo Scientific) at room temperature for 2 hours with shaking. After washing with buffer $(25 \mathrm{mmol} / \mathrm{L}$ Tris, $\mathrm{pH} 7.2,150 \mathrm{mmol} / \mathrm{L} \mathrm{NaCl}$,

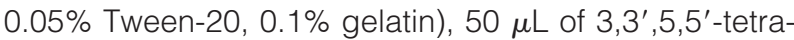
mentylbenzidine (Thermo Scientific) was added to the well and incubated at room temperature for 15 minutes before adding $50 \mu \mathrm{L}$ of $2 \mathrm{~mol} / \mathrm{L}$ sulfuric acid. Quantification of BSA was determined by measuring absorbance at $450 \mathrm{~nm}$ with a ThermoMax Microplate Reader (Molecular Devices) after verification with a standard curve using known amounts of biotin-BSA.

We measured paracellular permeability using two methods and in both dermal and pulmonary microvascular endothelium. After measurement of the baseline TEER, cells were exposed to $0.1 \mathrm{mmol} / \mathrm{L}$ NEM (Sigma) for 2 minutes followed by repeat measurement. Permeability of NEM-treated monolayers was also measured by the addition of FITC-dextran ( $50 \mu \mathrm{g} / \mathrm{mL}$; molecular weight, 70 $\mathrm{kDa}$ ) to the upper chamber of the transwell with removal of aliquots of media from both the upper and lower chambers 40 minutes later. Using appropriate filter sets, we measured the fluorescence in aliquots of the lower and upper chambers after subtraction of the appropriate blanks. Permeability was calculated as $P=\left[\left(\Delta C_{b} / \Delta t\right) \times\right.$ $\left.V_{b}\right] /\left(C_{a} \times A\right)$, where $\Delta C_{b} / \Delta t$ is the change in the basolateral concentration during the duration of the assay, $V_{b}$ is the volume of the basolateral chamber, $\mathrm{C}_{\mathrm{a}}$ is the apical concentration, and $\mathrm{A}$ is the area of the transwell. ${ }^{30}$ Changes in $V_{b}$ and $C_{a}$ were negligible during the experiment, and $\mathrm{C}_{\mathrm{b}}$ was much lower than $\mathrm{C}_{\mathrm{a}}$.

In other experiments, monolayers were incubated with $80 \mu \mathrm{mol} / \mathrm{L}$ Dynasore [or dimethyl sulfoxide (DMSO) as a solvent control] for 40 minutes followed by repeat measurement of the TEER. Other cells were incubated with Dynasore or DMSO, and $50 \mu \mathrm{g} / \mathrm{mL}$ of FITC-dextran was added simultaneously to the upper chamber of the transwell. Forty minutes later, flux of dextran into the lower chamber was calculated as explained above. To determine the effect of cooling to $<15^{\circ} \mathrm{C}$, cells were incubated at $14^{\circ} \mathrm{C}$ or $37^{\circ} \mathrm{C}$ for 40 minutes followed by repeat measurement of TEER. Alternatively, FITC-dextran was added to the upper chamber immediately before incubation at $14^{\circ} \mathrm{C}$ or $37^{\circ} \mathrm{C}$ and flux was calculated 40 minutes later, as described above. In some experiments, cells were pretreated with the nitric oxide synthase inhibitor nitroglycerine-nitro-L-arginine methyl ester (L-NAME) (Sigma; $100 \mu \mathrm{mol} / \mathrm{L}$ ) for 30 minutes before inhibition of transcytosis.

Permeability to dextran was also tested under $10 \mathrm{~cm}$ $\mathrm{H}_{2} \mathrm{O}$ of pressure. A column was added to the upper chamber of the transwells and was filled with $10 \mathrm{~cm}$ of media. Transwells were acclimatized to the new pressure during 5 hours, ${ }^{30}$ then the media in the column was replaced with media (also $10 \mathrm{~cm}$ in height) containing dextran and Dynasore or DMSO, and dextran flux was measured as described above with $80 \mu \mathrm{mol} / \mathrm{L}$ Dynasore or DMSO control.

\section{Electron Microscopy}

Transcytosis experiments were performed as described above, using gold-tagged albumin (6 nm, Electron Microscopy Sciences, Hatfield, PA). Fifteen minutes after incubation at $37^{\circ} \mathrm{C}$, cells on their transwells were fixed in $2 \%$ glutaraldehyde, after which the cells were washed four times with $0.1 \mathrm{~mol} / \mathrm{L}$ sodium cacodylate buffer. After the wash, the membranes were cut out of the transwell inserts. The cells were then fixed for 45 minutes in 1\% osmium tetroxide and $1 \%$ potassium ferrocyanide in cacodylate buffer. The samples were washed three times in buffer followed by twice in distilled water. The cells were stained for 30 minutes in $4 \%$ aqueous uranyl acetate then washed twice in distilled water. They were dehydrated through a graded series of ethanol and infiltrated and embedded in Epon (JEMBED 812). Sections were cut at $80 \mathrm{~nm}$, picked up on copper grids, and stained with uranyl acetate and lead citrate. Sections were examined using an FEI Tecnai 20 transmission electron microscope. Images were recorded with an AMT 16000 digital camera.

\section{Western Blot Analysis}

Lysates were analyzed by SDS-PAGE using 6\% to $12 \%$ polyacrylamide gels. Proteins were transferred to nitrocellulose membranes, blocked for 1 hour, and probed overnight with the primary antibody at $4^{\circ} \mathrm{C}$. After washing in PBS with Tween 20, blots were incubated with horseradish peroxidase-conjugated secondary antibodies for 1 hour, washed, and then visualized by enhanced chemiluminescence (Amersham). For quantitation, blots were scanned using Image J (National Institutes of Health), and the integrated intensity was normalized to the amount of protein loaded after correction for background.

\section{Microscopy and Immunofluorescence}

Analysis of the distribution and density of caveolin-1, F-actin, vascular endothelial cadherin (VE-cadherin), claudin-5, heparan sulfate, and internalized albumin was performed using spinning disk confocal microscopy (Zeiss Axiovert 200M microscope with $25 \times$ or $63 \times$ objectives; Zeiss, Jena, Germany). The unit is equipped with diode-pumped, solid-state laser lines (440, 491, 561, 638, and $655 \mathrm{~nm}$; Spectral Applied Research, Richmond Hill, ON), motorized XY stage (ASI), and a Zeiss focus drive. Images were acquired using back-thinned, electron-multiplied or conventional cooled, charge-couple device cameras (Hamamatsu, Shizuoka, Japan), driven by Volocity 4.1.1 software (Improvision, Coventry, England). In all cases, microscope settings were kept constant between conditions. All images were randomly chosen and were acquired as Z-stack projections (Z-interval, 0.2 to $0.5 \mu \mathrm{m})$.

Total internal reflectance fluorescence (TIRF) images were acquired on an Olympus cell ${ }^{\wedge}$ TIRF Motorized Multicolor TIRF module mounted on an Olympus IX81 microscope (Olympus, Hamburg, Germany). Samples were imaged using a $63 \times / 1.49$ objective with 491 -nm excita- 
tion lasers and MetaMorph acquisition software. Retention of the yellow fluorescent protein-tagged p21-binding domain (PBD-YFP) was determined by the ratio of lamellipodia or filopodia that still exhibited the PBD-YFP at 30 minutes compared with time 0 .

To immunostain for F-actin, VE-cadherin, and heparan sulfate, cells were rinsed in PBS, fixed for 30 to $60 \mathrm{~min}$ utes in $4 \%$ paraformaldehyde in PBS, incubated in $0.15 \%$ glycine for 10 minutes, permeabilized in $0.1 \%$ Triton X-100 for 20 minutes, and blocked for 1 hour. Cells were stained with Alexa Fluor 488 phalloidin (Molecular Probes), anti-VE-cadherin (Santa Cruz Biotechnology, Santa Cruz, CA), or anti-heparan sulfate (US Biological, Marblehead, MA) for 1 hour. For caveolin-1 and claudin-5, cells were fixed in methanol then put in blocking buffer for 1 hour at room temperature. The primary antibodies for caveolin-1 (Santa Cruz Biotechnology) and claudin-5 (Abcam, Cambridge, MA) were added for 1 hour at room temperature. Heparinase III treatment $(0.2$ $\mathrm{U} / \mathrm{mL}$ for 1 hour) was used as a negative control for heparan sulfate.

In some experiments, the internalization of membranebound albumin was compared under different conditions. Briefly, fluorophore-tagged albumin was added to cells in cold media and spun down at $16 \times g$ for 10 seconds; then the cells were incubated at $4^{\circ} \mathrm{C}$ for 10 minutes. Afterward, cells were rinsed with cold media and incubated at $37^{\circ} \mathrm{C}$ for 15 minutes. Cells were then fixed and processed as above.

As a control for endocytosis, a lipophilic styryl dye, $\mathrm{N}$-(3-triethylammoniumpropyl)-4-(p-diethylaminophenylhexatrienyl) pyridinium dibromide (FM 4-64, Invitrogen), ${ }^{31}$ was added to endothelial cells at a concentration of $5 \mu \mathrm{g} / \mathrm{mL}$ for 1 hour. Cells were then rinsed, fixed, and processed as above.

\section{Membrane Fraction Preparation}

Subcellular fractionation was performed as previously described. ${ }^{32}$ Briefly, dermal endothelial cells were grown to confluency in $10 \mathrm{~cm}$ dishes. Cells were rinsed with PBS then scraped into PBS and centrifuged at $400 \times g$ for 5 minutes to pellet the cells. The pellet was resuspended in hypotonic lysis buffer buffer containing $10 \mathrm{mmol} / \mathrm{L}$ Tris$\mathrm{HCl}, 5 \mathrm{mmol} / \mathrm{L} \mathrm{KCl}, 1 \mathrm{mmol} / \mathrm{L} \mathrm{MgCl}$, protease inhibitor, and $1 \mathrm{mmol} / \mathrm{L}$ DTT. Cells were further lysed using a Dounce Homogenizer (Wheaton, Millville, NJ) with 20 strokes. The mixture was centrifuged at $400 \times g$ for 5 minutes to pellet cell debris, and the supernatant was collected and subjected to repeat centrifugation at $16,000 \times g$ for 30 minutes. The pellet was resuspended in radioimmunoprecipitation assay buffer $(50 \mathrm{mmol} / \mathrm{L}$ Tris$\mathrm{HCl}, 150 \mathrm{mmol} / \mathrm{L} \mathrm{NaCl}, 1 \% \mathrm{NP}-40,0.5 \%$ deoxycholic acid, and $0.1 \%$ SDS) and incubated on ice for 30 minutes before analysis with Western blotting. Preparations were probed for the transferrin receptor as a positive control.

\section{Lipid Raft Isolation and Quantitation}

Dermal endothelial cells were grown to confluency in 6-cm dishes. After washing with PBS, cells were scraped and precipitated by centrifugation. Cells were lysed in $140 \mu \mathrm{L}$ of lysis buffer containing $25 \mathrm{mmol} / \mathrm{L}$ Tris- $\mathrm{HCl}, \mathrm{pH}$ 7.5, $150 \mathrm{mmol} / \mathrm{L} \mathrm{NaCl}, 10 \%$ sucrose, $1 \%$ Triton X-100, 1 $\mathrm{mmol} / \mathrm{L}$ dithiothreitol, and protease inhibitor cocktail $(\mathrm{R})$ for 30 minutes on ice. The lysate was then added to 0.66 $\mathrm{mL}$ of $60 \%$ OptiPrep (Axis-Shield, Oslo, Norway). To ensure complete lysis, cells were homogenized in an icecold Dounce Homogenizer (Wheaton) with 10 strokes. Cell lysates were then placed in an ultracentrifuge and overlaid with $0.8 \mathrm{~mL}$ of $40 \%, 30 \%$, and $20 \%$ OptiPrep. The gradients were centrifuged at $28,000 \times g$ at $4^{\circ} \mathrm{C}$ for 15 hours using an SW 55 Ti Rotor. Fractions were collected and analyzed by Western blot. Mouse anti-transferrin receptor antibody was from Invitrogen. Data were quantitated using ImageJ. After subtraction of background, the amount of caveolin-1 in the $20 \%$ fraction was divided by the total amount of caveolin-1. ${ }^{33}$

\section{Toxicity Assays}

Endothelial cell death was detected using trypan blue by enumerating the number of stained cells in 10 random fields ( $\times 20$ magnification). Apoptosis of endothelial cells was determined by staining with Annexin V-FITC (EBioscience, San Diego, CA) as per the manufacturer's instructions and analyzed by flow cytometry using a BD FACS Calibur cytometer (Becton Dickinson) and then imported into FlowJo 8.8.6 (TreeStar Inc., Ashland, OR).

\section{Transfection and siRNA}

For most experiments, primary human endothelial cells grown on coverslips or transwells were transfected with plasmids using Fugene HD (Roche) in accordance with the manufacturer's instructions and were used for experiments 24 hours later. For transfection of Rac constructs for cells on transwells, we used the Electro Square Porator according to the manufacturer's protocol (protocol 0394). The plasmids containing wild-type (WT) Rac, dominant-negative (DN) (T17N) Rac, dynamin-2 WT, K44A, and PBD-YFP were gifts from Sergio Grinstein and have been previously described. ${ }^{34,35}$ Dynamin-2 WT or K44A were co-transfected with green fluorescent protein (GFP) in a ratio of 9:1, and transfected cells were immunostained for dynamin to confirm that GFP-expressing cells also overexpressed dynamin-2. Clathrin heavy chain small interfering RNA (siRNA) (catalog no. SI00299880), caveolin-1 siRNA (FlexiTube Gene solution for catalog no. G5857), and the nontargeting siRNA control (catalog no. 1027280) were from Qiagen (Germantown, MD). Cells were transfected with siRNA using HiPerFect (Qiagen) in accordance with the manufacturer's instructions, subcultured to a transwell, and used in experiments 72 hours after transfection. Confirmation of knockdown by Western blotting was performed by making cell lysates directly from the transwells after the permeability experiments. Goat anti-clathrin heavy chain, rabbit anti-caveolin-1, mouse anti- $\beta$-actin, and horseradish peroxidase-conjugated secondary antibodies were from Santa Cruz Biotechnology. 


\section{Fluorescence Imaging in Isolated Perfused Mouse Lungs}

All experiments were performed in accordance with the Guide for the Care and Use of Laboratory Animals (Institute of Laboratory Animal Resources, seventh edition, 1996) and were approved by the Animal Care and Use Committee of the local government authorities. Real-time in situ fluorescence imaging in isolated perfused lungs of male C57BL/6 mice (25 $\pm 1 \mathrm{~g}$ of body weight; Charles River Laboratories, Pointe-Claire, Quebec) was performed as previously described. ${ }^{36}$ Briefly, isolated mouse lungs were constantly inflated with a gas mixture of $21 \% \mathrm{O}_{2}, 5 \% \mathrm{CO}_{2}$, and balance $\mathrm{N}_{2}$ at a positive airway pressure of $3 \mathrm{~cm} \mathrm{H}_{2} \mathrm{O}$. Lungs were perfused with KrebsHenseleit buffer containing $3 \%$ bovine serum albumin at $37^{\circ} \mathrm{C}$ and a constant perfusion rate of $1 \mathrm{~mL} / \mathrm{min}$. Membrane-permeant fura-2 AM (5 $\mu \mathrm{mol} / \mathrm{L}$; Invitrogen), FITCconjugated albumin (1 $\mathrm{mg} / \mathrm{mL})$, and tetramethylrhodamine isothiocyanate (TRITC) dextran (molecular weight, approximately 70,$000 ; 100 \mu \mathrm{g} / \mathrm{mL}$ ) (both from SigmaAldrich) were added to the perfusate and allowed to recirculate for 60 minutes in the presence or absence of either sphingosine-1-phosphate (S1P; $1 \mu \mathrm{mol} / \mathrm{L}$; Cayman, Ann Arbor, MI) or platelet-activating factor (50 $\mathrm{nmol} / \mathrm{L}$; Sigma-Aldrich). After 60 minutes, residual intravascular fluorescent dyes were washed out by lung perfusion with Krebs-Henseleit buffer.

Isolated perfused lungs were positioned on a custombuilt, vibration-free, motorized $X Y$ stage under an upright intravital microscope (Axiotech ${ }^{\text {vario }} 100 \mathrm{HD}$; Zeiss). The fluorescence of fura-2, FITC, and TRITC in the vascular wall and surrounding parenchyma of the lung venular capillaries was excited by monochromatic illumination (Polychrome IV; T.I.L.L. Photonics, Martinsried, Germany) at $\lambda=360 \mathrm{~nm}, 470 \mathrm{~nm}$ and $535 \mathrm{~nm}$, respectively. Fluorescence was collected through an approchromat objective (UAPO 40× W2/340; Olympus) and appropriate dichroic and emission filters (FT 425 and BP 505-530 for fura-2, DCLP 500 and LP 515 for FITC, and DCLP 530 and BP 535-585 for TRITC; all Zeiss) by a CCD camera (Sensicam; PCO, Kehlheim, Germany) and subjected to digital image analysis (TILLvisION 4.01; T.I.L.L. Photonics). In each lung, 10 to 15 single venular capillaries were viewed at a focal plane corresponding to their maximum diameter (16 to $32 \mu \mathrm{m}$ ). Images of fura-2, FITC, and
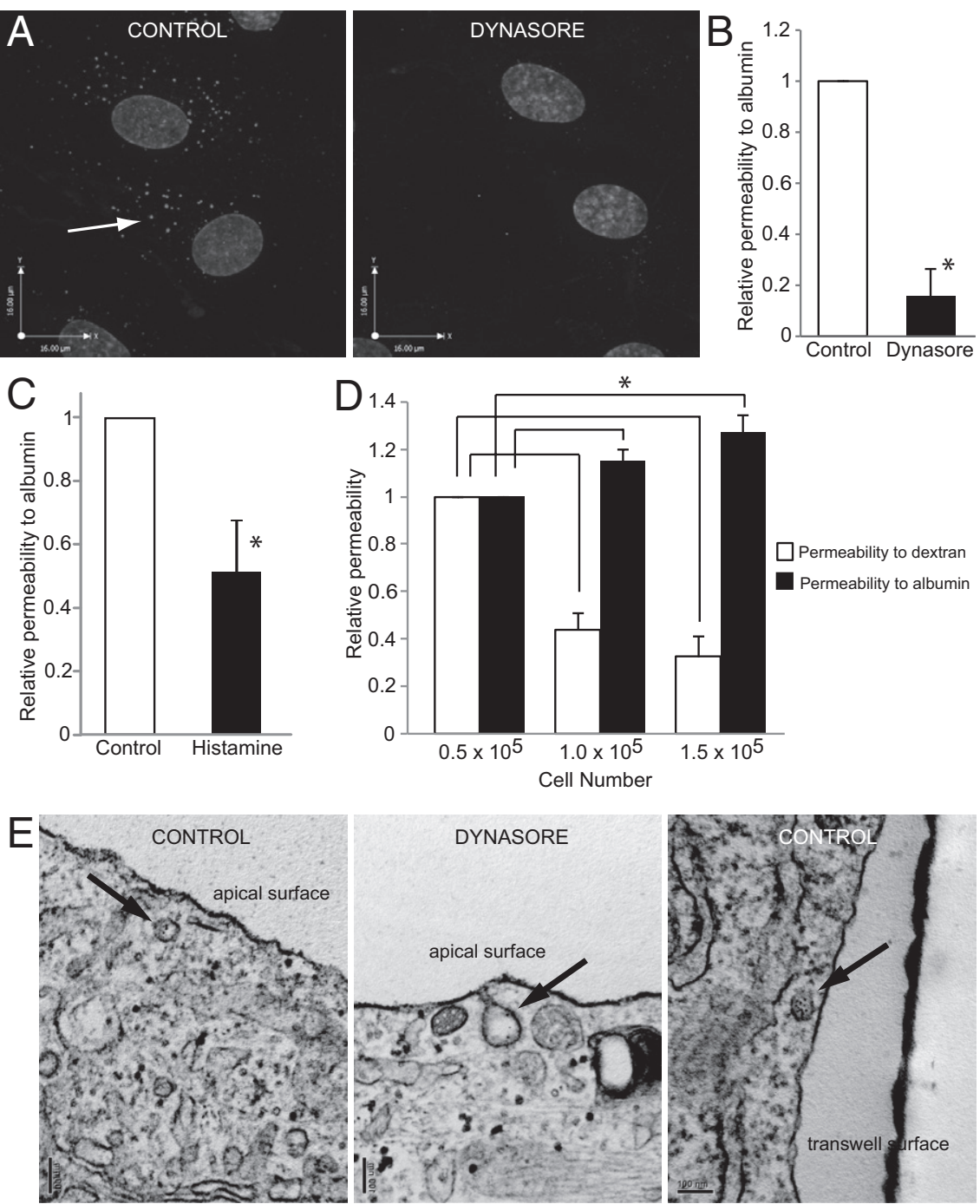

Figure 1. Human microvascular endothelium performs transcytosis in culture. A: Endothelium was incubated with FITC-conjugated albumin with solvent control (DMSO) (left) or $80 \mu \mathrm{mol} / \mathrm{L}$ Dynasore (right). Nuclei were stained with DAPI. Internalization of albumin (arrow) is inhibited by Dynasore. Images are Z-stack projections. Scale bar = $16 \mu \mathrm{m}$. Transcytosis assay was performed as described in Materials and Methods. Cells were treated with DMSO (control) or Dynasore $(n=7)$ (B) or histamine $(n=6)(\mathbf{C})(* P<0.05)$. Mean \pm $\mathrm{SD}$ (membrane-bound) albumin flux was $6.95 \pm$ $2.43 \times 10^{-6} \mathrm{~cm} / \mathrm{s}$ for control and $1.72 \pm 1.13 \times$ $10^{-6} \mathrm{~cm} / \mathrm{s}$ for Dynasore-treated monolayers. D: ELISA was performed using human pulmonary microvascular endothelium as described in Materials and Methods. Dextran is used as a measure of paracellular leak. The graph is representative of three independent experiments ( $x$ axis is cell number; ${ }^{*} P<0.05$ for all comparisons indicated) Mean \pm SD dextran flux was $2.06 \pm 0.07 \times 10^{-6}$ $\mathrm{cm} / \mathrm{s}, 0.89 \pm 0.19 \times 10^{-6} \mathrm{~cm} / \mathrm{s}$, and $0.65 \pm 0.20 \times$ $10^{-6} \mathrm{~cm} / \mathrm{s}$ for transwells seeded with 50,000 100,000 , and 150,000 cells, respectively. Mean biotin-conjugated albumin flux was $1.36 \pm 0.79 \times$ $10^{-7} \mathrm{~cm} / \mathrm{s}, 1.47 \pm 0.82 \times 10^{-7} \mathrm{~cm} / \mathrm{s}$, and $1.65 \pm$ $0.92 \times 10^{-7} \mathrm{~cm} / \mathrm{s}$ for transwells seeded with $50,000,100,000$, and 150,000 cells, respectively. E: Endothelium grown on transwells was incubated with 6-nm gold-tagged albumin (Au-Alb) with or without Dynasore. Left: Arrow denotes caveola containing Au-Alb near the apical surface of a cell Center: Caveola (arrow) containing Au-Alb that is unable to detach from the apical membrane of the cell due to Dynasore. Right: Caveola containing Au-Alb abutting the basolateral surface of control endothelial cells. Scale bar $=100 \mathrm{~nm}$. 
TRITC fluorescence were recorded in random sequence, and the mean ratio of FITC to fura2 and TRITC to fura2 fluorescence within the field of observation was calculated.

\section{Rac Activation Assay}

Rac activation was measured using the NewEast Biosciences (Malvern, PA) Rac Activation Kit according to the manufacturer's instructions. Briefly, dermal endothelial cells were grown to confluency on $10-\mathrm{cm}$ dishes. After appropriate experimental treatment, cells were washed with PBS, scraped into lysis buffer, kept on ice for 15 minutes, and then centrifuged. Supernatants were collected and analyzed by the Active Rac Pull-Down Assay. Samples containing GTP $\gamma S$ and GDP were used as positive and negative controls, respectively.

\section{Data and Statistical Analysis}

Unless otherwise indicated, all experiments were performed three times and data are expressed as mean and SE. Student's t-tests and analyses of variance were used as appropriate. $P<0.05$ was considered significant.

\section{Results}

\section{Primary Human Microvascular Endothelial Cells Perform Transcytosis}

We first devised assays to confirm that primary human microvascular endothelial cells grown in culture perform transcytosis. ${ }^{22}$ Endothelium grown on transwell filters was incubated with fluorescein-conjugated albumin in the upper chamber, and the transit of albumin to the lower chamber was quantified using a spectrofluorometer. To exclude paracellular leak, we limited our analysis to the transit of membrane-bound albumin ${ }^{21}$ from the apical to the basolateral surface because this would eliminate passive diffusion of albumin across intercellular gaps. As a control, transcytosis was blocked by the cellpermeable small-molecule inhibitor of dynamin, Dynasore, ${ }^{37}$ which prevents scission of caveolae from the apical plasma membrane. Dynasore is membrane permeable and has been shown to specifically inhibit dynamin with a reported half maximal inhibitory concentration of $15 \mu \mathrm{mol} / \mathrm{L}$. In initial experiments, we confirmed that Dynasore greatly attenuates the internalization of albumin by endothelial cells (Figure 1A).

As an additional control, we incubated cells with histamine after allowing them to bind albumin because histamine rapidly increases paracellular leak of endothelial monolayers by forming gaps between cells. ${ }^{8}$ We hypothesized that histamine should not increase the flux of albumin across the transwell if our assay was only measuring transcytosis. Indeed, our experiments demonstrate that cultured primary human microvascular endothelium performs transcytosis of albumin; as expected, inhibition of dynamin with Dynasore largely ablated transcytosis (Figure 1B), whereas incubation with histamine actually decreased it (Figure 1C).

To confirm our findings by a second method, we developed a streptavidin-based ELISA to measure transcytosis of biotin-conjugated albumin. We reasoned that the transcytosis of albumin would increase as a function of cell density until the monolayer was completely confluent. As a control, we measured the flux of dextran across the same transwell because dextran is not known to undergo transcytosis and passes via intercellular gaps. ${ }^{38,39}$ We observed that with increasing numbers of cells, the transcytosis of biotin-BSA across the transwell increased sig-
A
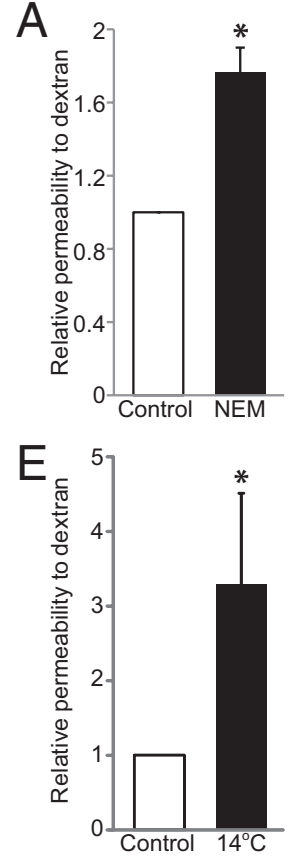
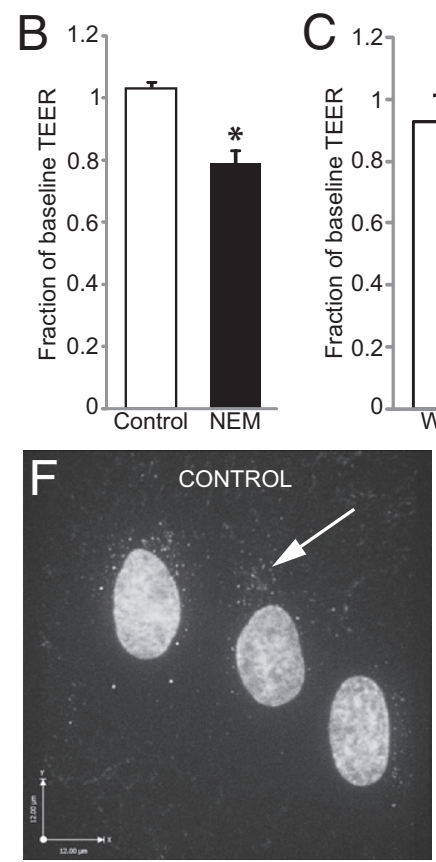
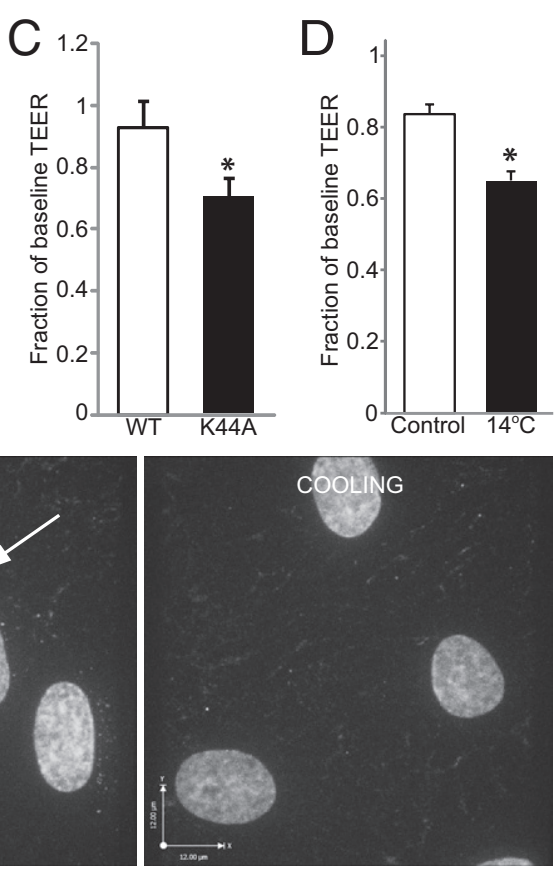

Figure 2. Inhibition of transcytosis by multiple methods induces paracellular leak. A: Endothelium grown on transwells was exposed to 0.1 $\mathrm{mmol} / \mathrm{L}$ NEM or control then incubated with FITC-conjugated dextran $\left({ }^{*} P<0.05\right)$. Mean \pm SD dextran flux was $0.24 \pm 0.17 \times 10^{-6} \mathrm{~cm} / \mathrm{s}$ for control and $0.40 \pm 0.27 \times 10^{-6} \mathrm{~cm} / \mathrm{s}$ for NEM. B: TEER was measured before and after exposure to NEM or control ( \pm SD baseline TEER: control, $25.0 \pm 1.6 \Omega \mathrm{cm}^{2} ; \mathrm{NEM}, 25.1 \pm 1.5 \Omega \mathrm{cm}^{2} ;{ }^{*} P<$ 0.05). C: Transfection with DN (K44A) dynamin-2 causes a marked decrease in TEER compared with transfection with WT dynamin-2 TEER was measured before and 24 hours after transfection. Transfection efficiency was approximately $70 \%$ and similar for both constructs (baseline TEER: WT, $21.6 \pm 0.7 \Omega \mathrm{cm}^{2} ; \mathrm{K} 44 \mathrm{~A}$ $\left.20.9 \pm 1.0 \Omega \mathrm{cm}^{2} ;{ }^{*} P<0.05\right)$. D: Endothelium was incubated at $37^{\circ} \mathrm{C}$ (control) or $14^{\circ} \mathrm{C}$. TEER was measured before and after the incubation (mean \pm SD baseline TEER: control, $25.0 \pm 1.3$ $\left.\Omega \mathrm{cm}^{2} ; 14^{\circ} \mathrm{C}, 25.8 \pm 1.7 \Omega \mathrm{cm}^{2} ; n=5 ; * P<0.05\right)$. E: Endothelium was incubated with FITC-conjugated dextran for 40 minutes at $37^{\circ} \mathrm{C}$ (control) or $14^{\circ} \mathrm{C}\left({ }^{*} P<0.05\right)$. F: Endothelium was incubated with FITC-conjugated albumin for 40 minutes at $37^{\circ} \mathrm{C}$ (left) or $14^{\circ} \mathrm{C}$ (right). Nuclei were stained with DAPI. Endosomes containing albumin (arrow, left) are absent in cells incubated at $14^{\circ} \mathrm{C}$. Images are Z-stack projections. 
nificantly, whereas the passage of dextran decreased (Figure 1D).

Finally, to confirm our findings visually, we performed transmission electron microscopy on endothelium that had been exposed to gold-tagged albumin (Figure 1E). As with the fluorescence assay, we used Dynasore as a control to block internalization (middle panel of Figure $1 \mathrm{E})$. We observed internalization of gold-tagged albumin by caveolae and the apparent transcytosis of the albumin to the basolateral surface. Thus, taken together, our results convincingly demonstrate that primary human microvascular endothelial cells in culture both possess caveolae and perform transcytosis of albumin in a dynamin-dependent manner.

\section{Inhibition of Transcytosis by Inhibiting SNARE Function Induces Paracellular Leak}

Earlier studies have demonstrated that the absence of caveolin-1 greatly reduces transcytosis and is associated with increased vascular permeability ${ }^{26,40}$; the latter has been attributed to increased paracellular leak or to changes in capillary pressure or the glycocalyx. ${ }^{27} \mathrm{Be}$ cause caveolin-1 has so many functions, ${ }^{28}$ it is not clear whether the increased permeability is due to the loss of transcytosis per se or due to the loss of caveolin-1. To inhibit transcytosis without depleting caveolin-1 levels, we took advantage of the fact that, like other cellular processes that require membrane fusion, transcytosis requires the activity of SNARE proteins. Uncoupling of SNARE complexes is dependent on the hexameric ATPase NEM-sensitive factor, and inhibition of this enzyme using NEM is known to block vesicular traffic ${ }^{41-43}$ and transcytosis. ${ }^{44}$ Incubation with NEM greatly inhibited internalization of albumin by both dermal and pulmonary endothelial cells (not shown). We found that exposure to NEM almost doubled the flux of dextran across the endothelial monolayer and significantly decreased the TEER (Figure 2, A and B). We considered the possibility that NEM might be toxic, even though higher concentrations and longer exposures have been used by others $^{19,41,42,44}$ without untoward effects. Under the conditions used in our experiments, NEM caused no toxic effects as assessed by phase-contrast microscopy (not shown), trypan blue exclusion, and annexin $\mathrm{V}$ binding ${ }^{45}$ to detect apoptosis (see Supplemental Figure S1, A and $\mathrm{B}$, at http://ajp.amjpathol.org).

\section{Inhibition of Transcytosis by a Molecular Approach Induces Paracellular Leak}

Although NEM is a classic inhibitor of SNARE proteins, it lacks specificity. To inhibit transcytosis by a second, more specific method, we transfected endothelial cells with dynamin-2 K44A, a mutant form of dynamin-2 that is unable to bind GTP and acts in a DN manner. ${ }^{46}$ As a control, we transfected other cells with WT dynamin-2. The transfection efficiencies for both constructs were equivalent and high (approximately $70 \%$ at 24 hours). DN dynamin-2 significantly reduced TEER compared with WT, indicating an increase in paracellular permeability (Figure 2C). Thus, inhibition of transcytosis by a specific molecular method led to an increase in paracellular leak.

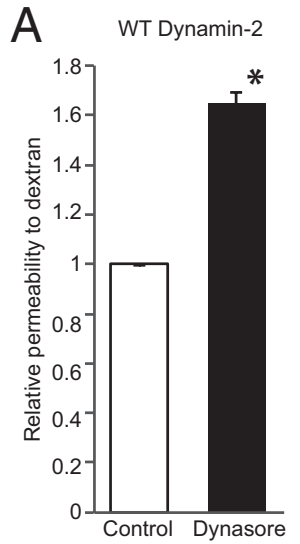

B Dynamin-2 K44A
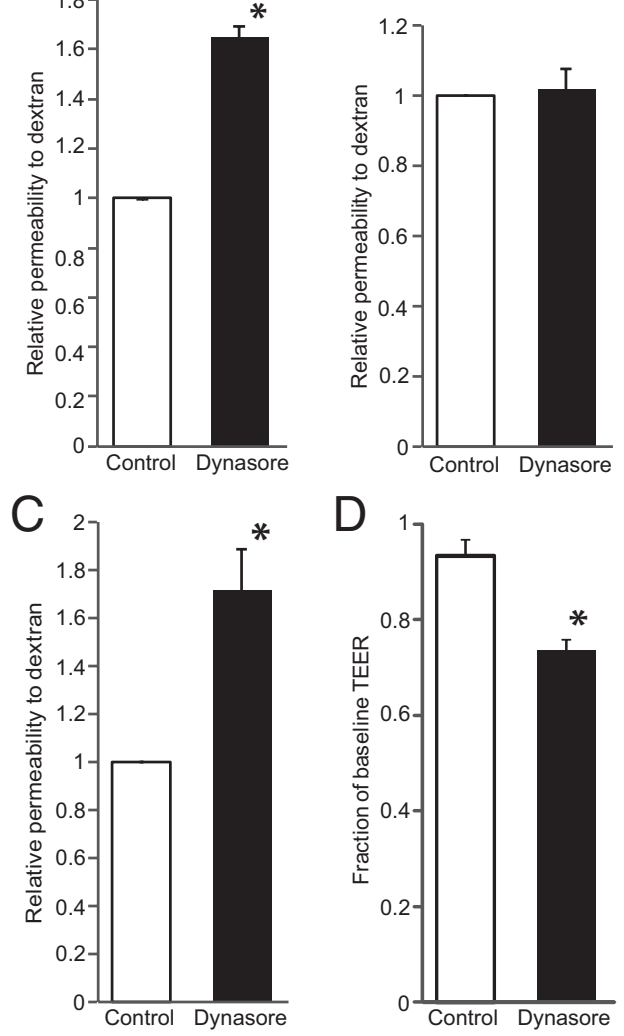

$E$
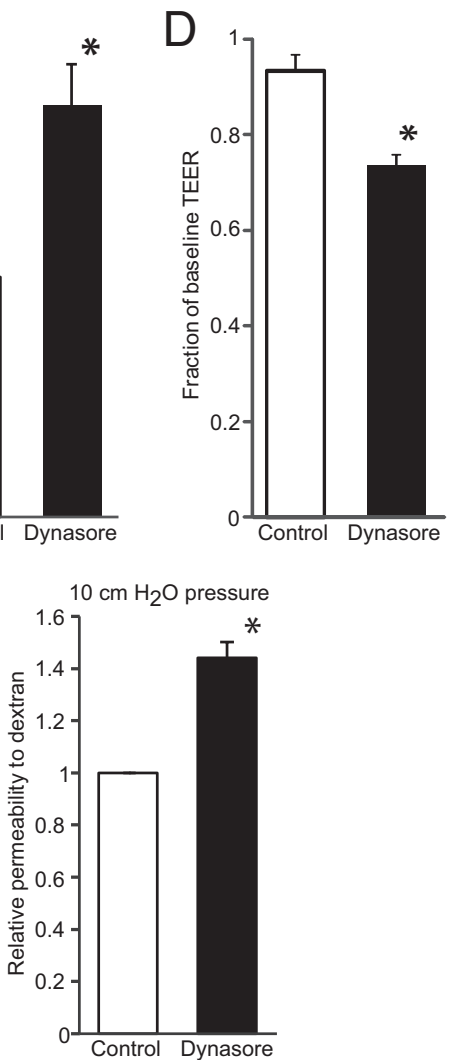

Figure 3. Dynasore specifically inhibits dynamin and induces paracellular leak A: Dynasore increases dextran flux in cells transfected with WT dynamin-2 ( $P<$ $0.05)$. Mean $\pm \mathrm{SD}$ dextran flux was $0.63 \pm 0.38 \times 10^{-6} \mathrm{~cm} / \mathrm{s}$ for control and $1.01 \pm 0.58 \times 10^{-6} \mathrm{~cm} / \mathrm{s}$ for Dynasore. B: Dynasore does not increase dextran flux in cells transfected with dynamin-2 K44A. Mean \pm SD dextran flux was $0.99 \pm 0.28 \times 10^{-6} \mathrm{~cm} / \mathrm{s}$ for control and $1.01 \pm 0.32 \times 10^{-6} \mathrm{~cm} / \mathrm{s}$ for Dynasore. C: Endothelium was exposed to Dynasore or DMSO and FITC-conjugated dextran for 40 minutes. Permeability to dextran was calculated relative to control $\left.{ }^{*} P<0.05\right)$. Mean $\pm \mathrm{SD}$ dextran flux was $0.55 \pm 0.21 \times 10^{-6} \mathrm{~cm} / \mathrm{s}$ for control and $0.88 \pm 0.28 \times 10^{-6} \mathrm{~cm} / \mathrm{s}$ for Dynasore. D: The TEER of endothelial cells was measured before and after incubation with Dynasore or DMSO for 40 minutes (mean \pm SD baseline TEER: control, $25.0 \pm 0.4 \Omega \mathrm{cm}^{2}$; Dynasore, $25.4 \pm 0.4$ $\left.\Omega \mathrm{cm}^{2}\right)\left({ }^{*} P<0.05\right)$. E: Endothelium was exposed to $10 \mathrm{~cm} \mathrm{H}_{2} \mathrm{O}$ pressure for 5 hours then, while still under pressure, treated with Dynasore or DMSO and FITC-conjugated dextran for 40 minutes. Permeability to dextran was calculated relative to control $\left({ }^{*} P<0.05\right)$. Mean $\pm \mathrm{SD}$ dextran flux was $0.87 \pm 0.24 \times 10^{-6}$ $\mathrm{cm} / \mathrm{s}$ for control and $1.22 \pm 0.30 \times 10^{-6} \mathrm{~cm} / \mathrm{s}$ for Dynasore. 


\section{Inhibition of Transcytosis by Cooling also Induces Paracellular Leak}

Many endocytic processes, such as transcytosis, are inhibited at temperatures $<15^{\circ} \mathrm{C} .^{24,47,48}$ Indeed, incubation at $14^{\circ} \mathrm{C}$ completely blocked the internalization of albumin by primary human microvascular endothelium (Figure 2F). Cooling also significantly increased paracellular flux of dextran and decreased the TEER of the monolayer (Figure 2, D and E). This effect was seen in both dermal and pulmonary microvascular endothelium (latter not shown). Importantly, incubation at $14^{\circ} \mathrm{C}$ was not toxic to the cells as assessed by trypan blue exclusion and annexin $\mathrm{V}$ staining (see Supplemental Figure S1, C and D, at http://ajp.amjpathol.org).

\section{Inhibition of Transcytosis by Dynasore Induces Paracellular Leak}

One disadvantage of a molecular approach is the inability to block transcytosis acutely, making it difficult to distinguish immediate from delayed compensatory effects. In addition, although incubation at $14^{\circ} \mathrm{C}$ acutely inhibits endocytic traffic, its lack of specificity makes the determination of the molecular mechanism(s) difficult. One solution is the dynamin inhibitor Dynasore, which blocks dynamin activity within minutes and has been shown to be highly specific. ${ }^{37}$ We first confirmed its specificity in our own hands by transfecting cells with DN dynamin-2, reasoning that such cells should have no additional phenotype (ie, increased paracellular leak) when exposed to a dynamin inhibitor. Thus, although Dynasore induced paracellular leak in dynamin-2 WT transfected cells, it had no effect on the endothelial cells transfected with the K44A mutant (Figure 3, A and B).

Having confirmed its specificity, we then observed that Dynasore increased the flux of 70-kDa dextran across endothelial monolayers and decreased the TEER (Figure $3, \mathrm{C}$ and D). This effect was also seen in primary pulmo- nary endothelium (not shown). It is important to note that this experiment is different from that described in Figure 1 because it involves the flux of dextran (which is not transported by transcytosis ${ }^{39}$ ) instead of membranebound albumin. In addition, Dynasore increased the flux of albumin across the transwell if binding to the endothelial membrane was not performed first (not shown).

Paracellular permeability across the endothelium in vivo is affected not just by diffusion gradients but also by transmural pressure and the resultant convective transport. ${ }^{49}$ To determine whether our observations held under conditions that included the convective transport associated with vessels under pressure, we repeated the experiment at a transmural pressure of $10 \mathrm{~cm} \mathrm{H}_{2} \mathrm{O}$. Under these conditions, Dynasore continued to induce a marked increase in paracellular leak (Figure 3E). Importantly, Dynasore did not induce cell death or apoptosis under the conditions tested, and cells treated with Dynasore appeared healthy; this finding suggests that the increase in paracellular leak was not due to toxicity (see Supplemental Figure S1, E and F, at http://ajp.amjpathol. org). Finally, although dynamin resides at both the plasma membrane and the Golgi, the effect of Dynasore was not due to impairment of Golgi function because dissolution of the Golgi by brefeldin $A^{50}$ did not induce paracellular leak (not shown).

\section{Induction of Paracellular Leak Is Not Due to Interference With Clathrin-Mediated Endocytosis}

Because SNAREs and dynamin are required for clathrinmediated endocytosis, it was conceivable that the inhibitors used in this study were exerting their effects through blockade of clathrin-mediated endocytosis rather than inhibition of caveolar uptake. To resolve this issue, we knocked down clathrin heavy chain by siRNA in primary human microvascular endothelium before blocking transcytosis. We achieved a reduction in clathrin levels of
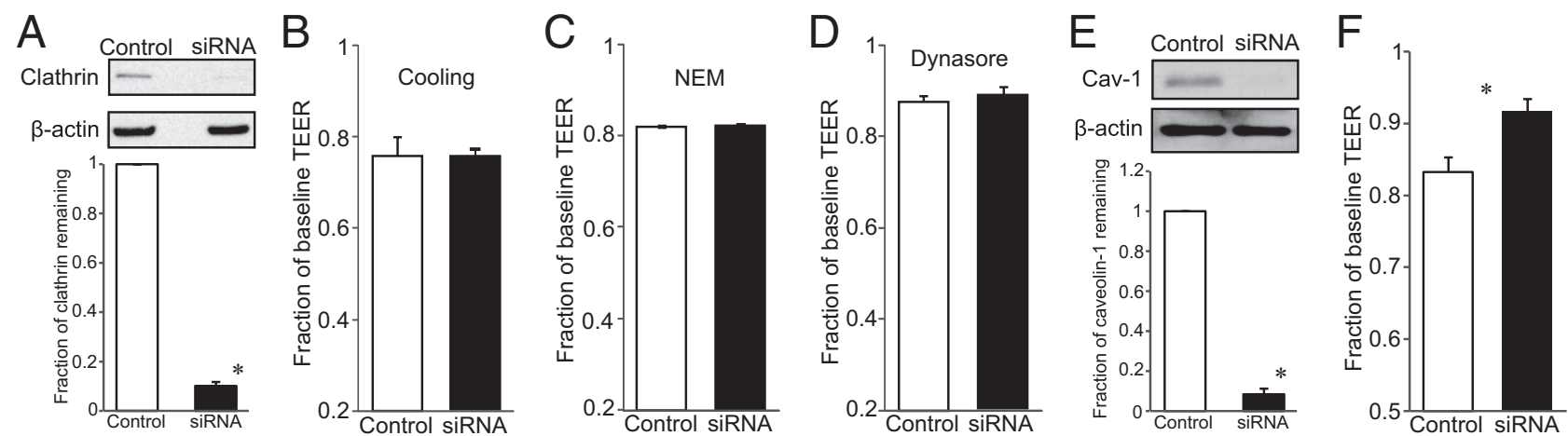

Figure 4. Inhibition of transcytosis induces paracellular leak in cells depleted of clathrin. A: Endothelium was transfected with siRNA to clathrin heavy chain or nontargeting control siRNA. Seventy-two hours after transfection, whole-cell lysates were probed for clathrin by Western blot. The lower panel shows $\beta$-actin as a loading control, whereas the histogram shows degree of knockdown $\left(n=4 ;{ }^{*} P<0.05\right)$. B-D: Cooling $\left(\mathbf{B} ;\right.$ mean \pm SD baseline TEER: negative control, $22.4 \pm 1.7 \Omega \mathrm{cm}{ }^{2}$; siRNA, $\left.23.9 \pm 2.0 \Omega \mathrm{cm}^{2}\right)$, NEM $\left(\mathbf{C}\right.$; mean \pm SD baseline TEER: negative control, $20.9 \pm 1.9 \Omega \mathrm{cm}^{2}$; siRNA, $\left.20.9 \pm 1.9 \Omega \mathrm{cm}^{2}\right)$, and Dynasore $(\mathbf{D}$; mean \pm SD baseline TEER: negative control, $24.3 \pm 1.0 \Omega \mathrm{cm}^{2}$; siRNA, $23.1 \pm 0.4 \Omega \mathrm{cm}^{2}$ ) induce leak to the same degree in cells depleted of clathrin compared with cells with normal levels of clathrin. Endothelium depleted of clathrin (siRNA) or not (control) was cooled to $14^{\circ} \mathrm{C}$, incubated with $0.1 \mathrm{mmol} / \mathrm{L} \mathrm{NEM}$, or incubated with $80 \mu \mathrm{mol} / \mathrm{L} \mathrm{Dynasore}$, and the effect on TEER was assessed. E: The effect of Dynasore is significantly attenuated in cells depleted of caveolin-1 compared with cells with normal levels. F: Endothelium was depleted of caveolin-1 (siRNA) or not (control) and the TEER was measured before and after treatment with Dynasore (mean \pm SD baseline TEER: negative control, $25.4 \pm 2.9 \Omega \mathrm{cm}^{2} ;$ siRNA, $\left.22.7 \pm 2.2 \Omega \mathrm{cm}^{2}\right)\left({ }^{*} P<0.05\right)$. 
almost $90 \%$ at 72 hours (Figure 4A). However, inhibition of transcytosis by Dynasore (and NEM and cooling to $14^{\circ} \mathrm{C}$ ) still induced paracellular leak to the same degree as in cells with normal levels of clathrin (Figure 4, B-D). Thus, the effect we observed is not simply a nonspecific reaction to blockade of endocytosis. To prove that our findings reflected inhibition of transcytosis per se, we knocked down caveolin-1 by siRNA (Figure 4E). Under these conditions, endothelial cells are known to be depleted of caveolae and do not perform transcytosis. ${ }^{20,40}$ Despite seeding equal numbers of cells, the baseline TEER was slightly lower in cells knocked down for caveolin-1 compared with control. This finding is not unexpected given the reported increase in paracellular permeability under such conditions. ${ }^{40}$ Under conditions in which caveolin-1 was depleted by approximately $90 \%$, the effect of Dynasore was markedly reduced (Figure 4F). This finding suggests that transcytosis is required for the effect that we observed.

\section{Inhibition of Transcytosis Does Not Decrease or Redistribute Caveolin-1 Levels}

To determine the mechanism of the increased paracellular leak, we focused on the dynamin inhibitor Dynasore because it functions acutely and its mechanism of action is specific and known. Given that caveolin-1-deficient mice demonstrate increased vascular leak, ${ }^{26}$ we considered the possibility that inhibition of transcytosis by Dynasore might have an effect on caveolin-1 levels or its cellular distribution. We assessed caveolin-1 by immunofluorescence and by Western blotting of whole cell lysates (not shown) and lipid raft preparations. Dynasore did not alter caveolin-1 density or distribution by immunofluorescence (Figure 5A) and did not deplete caveolin-1 levels in lipid rafts (Figure 5B).

The increase in paracellular leak observed in caveolin1-deficient mice has been attributed to increased production of nitric oxide because endothelial nitric oxide synthase is constitutively inhibited by caveolin-1. ${ }^{26,51}$ In those experiments, treatment of caveolin-1-deficient mice with the nitric oxide synthase inhibitor L-NAME restored microvascular integrity. ${ }^{26}$ Thus, we considered the possibility that inhibition of transcytosis might induce endothelial nitric oxide synthase activity, even though we were not able to detect any change in caveolin- 1 and even though caveolar internalization has been reported to be required for endothelial nitric oxide synthase activation. ${ }^{52}$ Production of nitric oxide by resting endothelium is quite low (not shown), making it difficult to exclude small changes. However, we pretreated endothelial monolayers with L-NAME and observed no effect on the induction of paracellular leak that was induced by Dynasore (Figure 5C). Thus, although we cannot definitively exclude it, increased nitric oxide production is unlikely to account for the increase in paracellular leak.
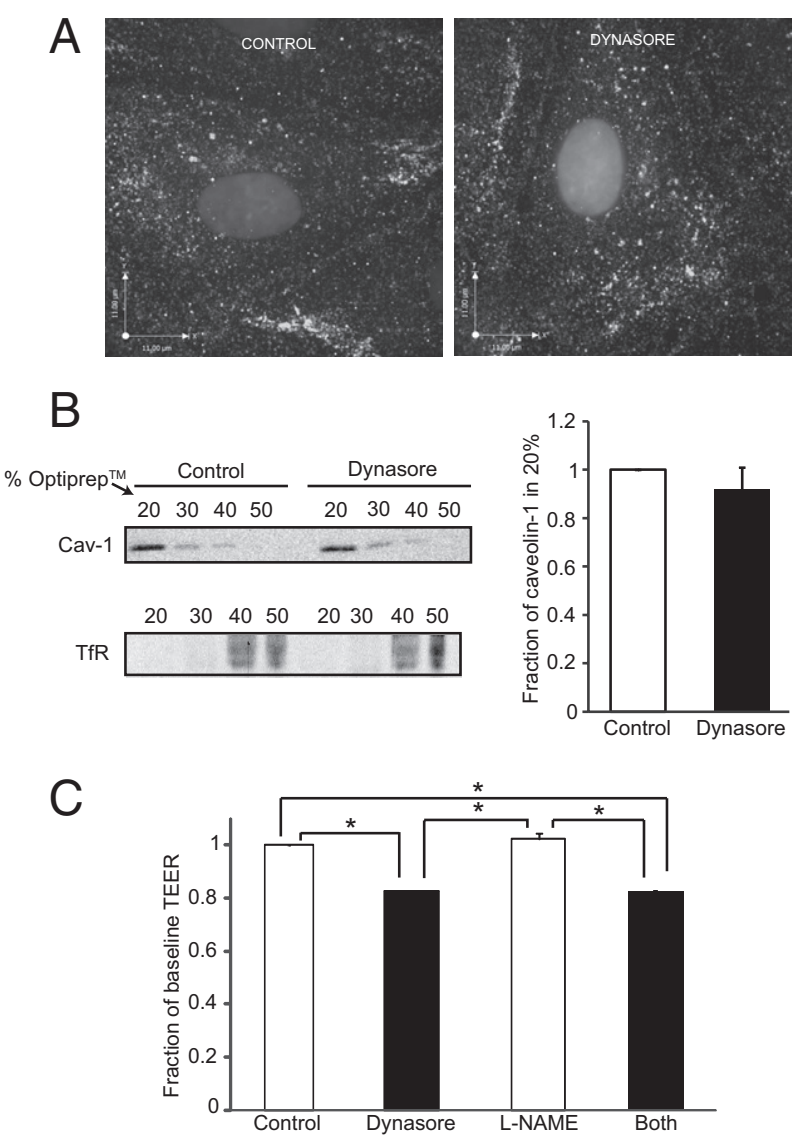

Figure 5. Inhibition of transcytosis does not decrease or redistribute caveolin-1. A: Immunofluorescence staining for caveolin-1 (cav-1) in endothelial cells incubated with (right) or without (left) Dynasore. Images are Z-stack projections and are representative of three independent experiments. B: Levels of cav-1 in lipid rafts are not diminished with Dynasore treatment. Western blot for cav-1 in different density fractions of endothelial cells with or without incubation for 40 minutes with Dynasore. The transferrin receptor (TfR) was used as a control for nonlipid raft fractions. The fraction of protein in the lipid raft ( $20 \%$ fraction) was calculated relative to total protein $(n=4)$. C: Inhibition of nitric oxide synthase with L-NAME does not prevent induction of paracellular leak by Dynasore. Endothelium was preincubated with L-NAME for 30 minutes followed by Dynasore. TEER was measured before and after incubation. Data represent mean $\pm \mathrm{SD}\left(n=2 ;{ }^{*} P<0.05\right)$.

\section{Inhibition of Transcytosis Does Not Affect Junctional Proteins or the Glycocalyx}

One of the canonical pathways regulating paracellular permeability is the internalization of VE-cadherin from the plasma membrane. ${ }^{13} \mathrm{~A}$ priori, this seemed unlikely to account for the increased paracellular leak because inhibition of transcytosis would not be expected to lead to increased uptake of VE-cadherin. As expected, Dynasore had no effect on the total amount of VE-cadherin, its fraction in the membrane, or its distribution as assessed by immunofluorescence (Figure 6, A and B). Similarly, Dynasore had no effect on the distribution of the tight junction protein claudin-5 (Figure 6C) or on the distribution or density of the glycocalyx component heparan sulfate (Figure 6D). Thus, at least initially, inhibition of transcytosis using Dynasore does not exert its primary effect on intercellular junctions or on the glycocalyx. 

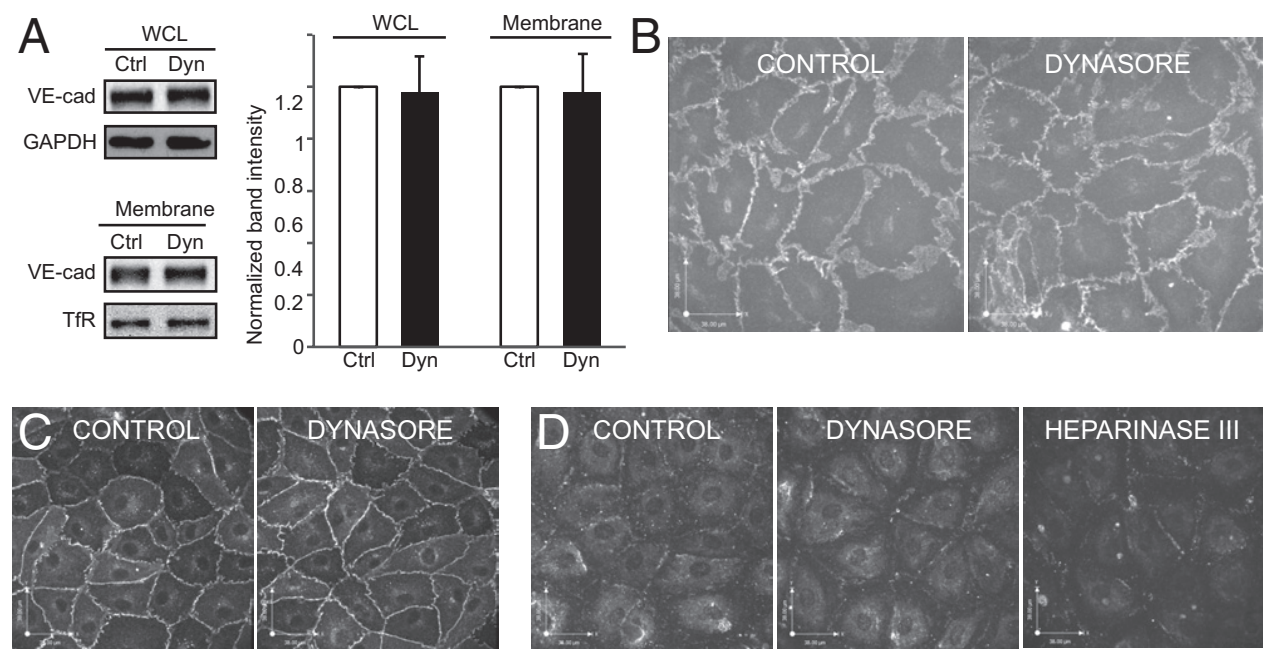

Figure 6. Treatment with Dynasore (Dyn) does not alter levels or distribution of VE-cadherin. A: Western blot for VE-cadherin in whole cell lysate (WCL) and membrane preparations in cells treated with Dynasore or DMSO [control (Ctrl)]. Membrane was stripped and reprobed for glyceraldehyde-3-phosphate dehydrogenase (GAPDH) as a loading control or probed for the transferrin receptor (TfR) to confirm successful membrane isolation. Quantitation was performed using ImageJ. B-D: Treatment with Dynasore does not alter the distribution of VE-cadherin (B), claudin-5 (C), or heparan sulfate (D). Immunofluorescence staining for the junctional proteins (B and $\mathbf{C}$ ) in endothelial cells incubated with (right) or without (left) Dynasore. D: Treatment with Dynasore does not alter the density or distribution of heparan sulfate. Cells were incubated with (middle) or without (left) Dynasore. Heparinase III treatment was used as a negative control (right). Images are Z-stack projections and are representative of three independent experiments.

\section{Inhibition of Transcytosis Is Associated With Remodeling of the Actin Cytoskeleton}

Instead, we reasoned that the rapid changes in paracellular permeability after inhibition of transcytosis were likely associated with remodeling of the actin cytoskeleton, similar to the leak induced by certain inflammatory mediators. ${ }^{53,54}$ We observed that inhibition of transcytosis by Dynasore was associated with a significant thinning of cortical actin (Figure 7, A and B). This loss of cortical actin was not due to generalized disassembly of actin because the total level of F-actin remained unchanged (Figure 7C).

We hypothesized that the loss of cortical actin likely stemmed from a change in Rac-GTP levels or its intracellular distribution. Treatment with Dynasore had no effect on total cellular Rac-GTP levels (Figure 7D). However, previous literature on phagocytosis had suggested that dynamin could regulate the intracellular traffic of Rac. ${ }^{55}$ We therefore transfected primary endothelial cells with PBD-YFP; the latter construct consists of the p21 Rac-GTP-binding domain of PAK (a known effector of Rac) fused to YFP and is a sensitive indicator of Rac activity in live cells. ${ }^{35}$ To distinguish plasmalemmal or juxtaplasmalemmal Rac-GTP from the cytosolic protein, we analyzed the distribution of PBD-YFP at the basal membrane of confluent endothelial cells by total internal reflectance fluorescence microscopy (TIRFM). This sensitive technique permits cellular imaging to be restricted to only the basal 100 to $150 \mathrm{~nm}$ of the cell, ${ }^{56}$ decreasing confounding by cytosolic fluorescence. TIRFM revealed enrichment of PBD-YFP at the lamellipodia and filopodia of resting endothelium that was further enhanced by treatment with S1P, a known Rac agonist. ${ }^{57}$ Remarkably, relative to control cells in which active Rac remained constant or increased over time, Dynasore-treated cells demonstrated a rapid and marked translocation of the Rac-GTP probe from cellular edges, consistent with the effects of Dynasore on cortical actin and paracellular leak (Figure 7, E and F).

\section{Decreasing Paracellular Leak Causes Induction of Transcytosis}

We considered the possibility that induction of paracellular leak could be an indirect consequence rather than a direct result of the inhibition of transcytosis. We believe that this is unlikely given the consistent results obtained using multiple distinct methods of inhibition. However, a powerful way of establishing the connection between transcytosis and paracellular permeability would be to demonstrate the reverse relationship. In particular, we hypothesized that inhibition of paracellular leak would induce transcytosis. Furthermore, the changes we had observed in cortical actin and Rac were reminiscent of reciprocal changes induced by S1P. S1P is one of the few molecules that are well known to stabilize endothelial barrier integrity, ${ }^{1}$ an action mediated in large part through Rac-dependent increased generation of cortical actin. ${ }^{57}$ As expected, S1P caused a decrease in paracellular permeability (Figure 8A), whereas permeability to dextran (70 $\mathrm{kDa}$ ), already low at baseline, was unaffected (Figure 8D). Treatment with S1P greatly attenuated the loss of cortical actin induced by Dynasore and the induction of paracellular leak (Figure 8, B, C, and E). Remarkably, the reduction in paracellular leak by S1P was associated with a significant increase in the transcytosis of albumin (Figure 8D).

We next moved to an ex vivo model to validate our in vitro findings. To do so, we performed real-time in situ fluorescence imaging in isolated perfused mouse lungs. ${ }^{36}$ Membrane-permeant fura-2 AM was used to label endothelial cells, and FITC-conjugated albumin and TRITC-conjugated dextran were added simultaneously to the lung perfusate (Figure 9A). As a positive control, 

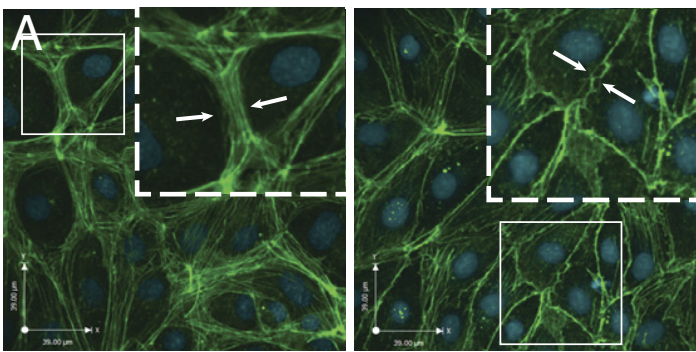

B

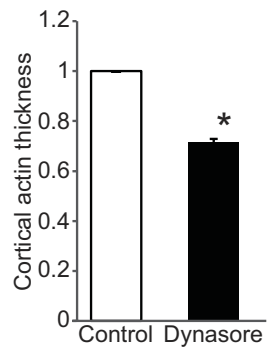

C

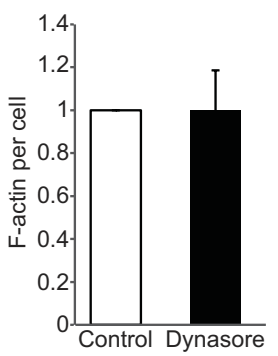

$\mathrm{F}$

F s1P

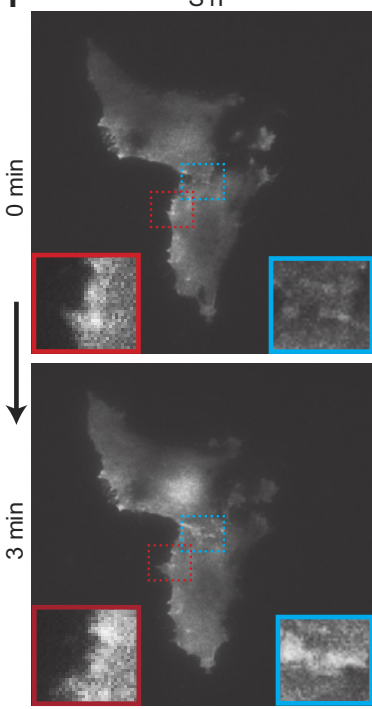

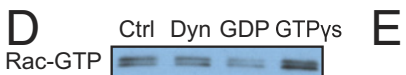

Total Rac

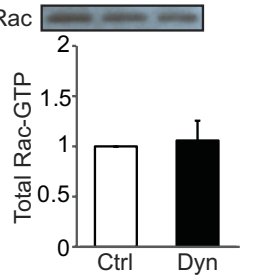

Control
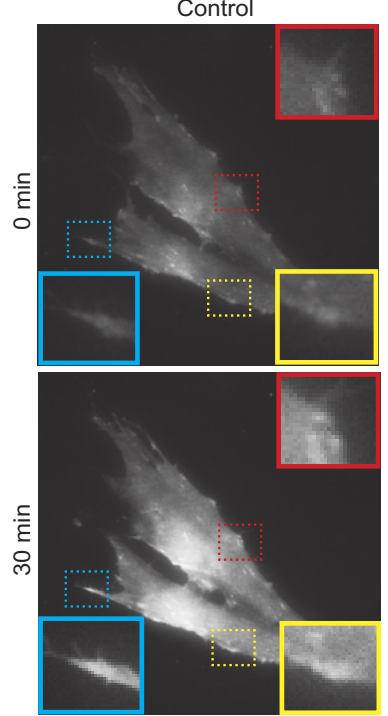

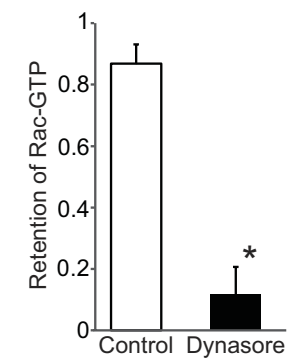

Dynasore
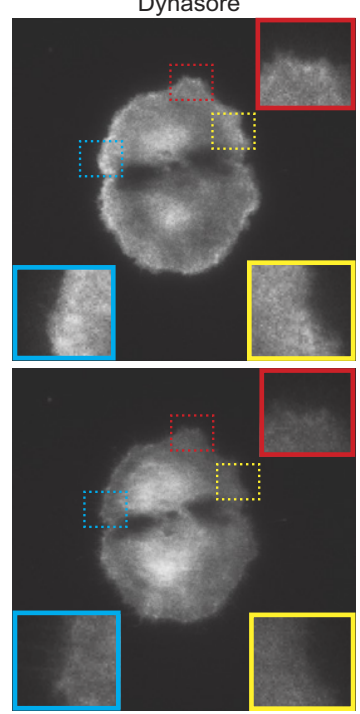

Figure 7. Inhibition of transcytosis by Dynasore (Dyn) results in a loss of cortical actin due to translocation of active Rac. A: Immunofluorescence staining for F-actin in endothelial cells incubated with (right) or without (left) Dynasore. Dashed white box shows a magnification of the portion of the image outlined with the solid white box. Arrows indicate cortical actin. B: Using ImageJ, three measurements of cortical actin thickness were taken for each cell (each a a different cell-to-cell junction) using Z-stack projections. Measurements were taken from $>700$ cells $\left({ }^{*} P<0.05\right)$. C: Intensity of F-actin was measured for $>50$ randomly selected fields and divided by the number of cells. D: Endothelial cells were treated with Dynasore or DMSO (ctrl). Cell lysates were immunoprecipitated with an anti-Rac-GTP antibody $(n=4)$; lysates loaded with GDP or GTP $\gamma \mathrm{S}$ served as controls. Total Rac is shown in the lower panel. $\mathbf{E}$ and $\mathbf{F}$ : Cells transfected with PBD-YFP were imaged live using TIRFM to analyze the distribution of active Rac at the cell membrane (F; quantitation in $\mathbf{E}$ ). Images were captured at 0 minutes and 30 minutes after treatment with DMSO or Dynasore. $\mathrm{S} 1 \mathrm{P}(1 \mu \mathrm{mol} / \mathrm{L})$ was used as a positive control for Rac activation. Colored boxes denote areas enlarged for insets. Dynasore caused a significant translocation of active Rac from cellular edges (E). Monolayers were confluent, but only transfected cells are visible $\left(n=5 ;{ }^{*} P<0.05\right)$. treatment with the potent inflammatory mediator plateletactivating factor caused a marked extravasation of dextran from the vasculature (Figure 9C). In contrast, treatment with S1P caused a significant translocation of intravascular albumin with no extravasation of dextran (Figure 9B). Importantly, the fluorescent signals for albumin and fura-2 overlapped almost perfectly, indicating transcellular passage of albumin.

\section{Inhibition of Rac Activity Reduces the Internalization of Membrane-Bound Albumin by Microvascular Endothelium}

The data from Dynasore and S1P (a known Rac agonist) strongly implicated an unsuspected role for Rac in regulating albumin internalization. To validate this notion, we transfected primary human microvascular endothelium with GFP-tagged WT or DN (T17N) Rac. ${ }^{35}$ We reasoned that if induction of transcytosis by S1P was mediated by
Rac activation, impairment of Rac should prevent the internalization of membrane-bound albumin. Endothelial cells that overexpressed WT Rac variably demonstrated normal or increased albumin internalization (Figure 10A). We observed that expression of DN Rac significantly attenuated the uptake of albumin compared with both untransfected and WT-Rac-transfected cells (Figure 10B), without affecting endocytosis (Figure 10C). Concordantly, despite incomplete transfection of the endothelial monolayer (approximately $75 \%$ ), expression of DN Rac led to a significant increase in paracellular leak (Figure 10D). These data imply that active Rac, through its effects on actin and on albumin uptake, is a key player at the junction of paracellular leak and transcytosis.

\section{Discussion}

Increased vascular permeability is the hallmark of inflammation and is thought to facilitate the emigration of leu- 
A

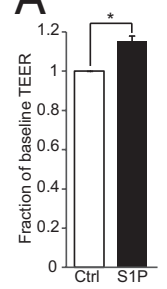

C

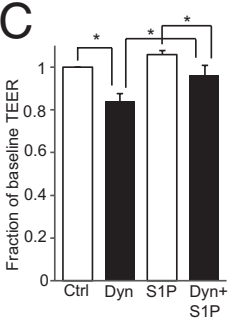

$\mathrm{D}$

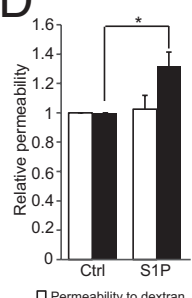

पPermeability to dextran
Q Permeability to albumin
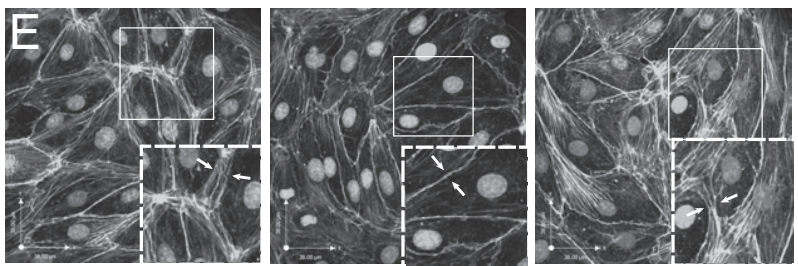

Figure 8. Reduction of paracellular leak by S1P causes induction of transcytosis. A: S1P decreases paracellular leak as measured by TEER. TEER was measured before and after incubation with methanol [solvent control (Ctrl)] or $1 \mu \mathrm{mol} / \mathrm{L} \mathrm{S1P}$ (mean \pm SD baseline TEER: control, $35.5 \pm 1.3 \Omega \mathrm{cm}^{2} ; \mathrm{S} 1 \mathrm{P}$, $\left.34.3 \pm 0.7 \Omega \mathrm{cm}^{2}\right)$. Results are normalized to control ( $\left.{ }^{*} P<0.05\right)$. B: Treatment with S1P attenuates Dynasore (Dyn)-induced loss of cortical actin compared with methanol-treated cells (control). Immunofluorescence staining for F-actin (E) in cells incubated for 40 minutes under control conditions (left), with Dynasore (center), or with Dynasore and S1P (right). Arrows indicate cortical actin. Images are Z-stack projections and are representative of three independent experiments (quantitation in B). Measurements were taken from $>800$ cells $\left({ }^{*} P<0.05\right)$. C: The TEER of endothelial cells was measured before and after 40 minutes incubation with control, Dynasore, S1P, or Dynasore and S1P (mean \pm SD baseline TEER: control, $35.6 \pm 1.7 \Omega \mathrm{cm}^{2}$; Dynasore, $33.9 \pm 1.7 \Omega \mathrm{cm}^{2}$; $\mathrm{S} 1 \mathrm{P}, 33.6 \pm 1.8 \Omega \mathrm{cm}^{2}$; Dynasore and $\mathrm{S} 1 \mathrm{P}, 33.9 \pm$ $\left.1.7 \Omega \mathrm{cm}^{2}\right)\left(n=4 ;{ }^{*} P<0.05\right)$. D: S1P increases transcytosis of albumin compared with methanol-treated cells (control) but not permeability to dextran. Black bars indicate relative permeability to albumin (transcytosis), whereas white bars indicate relative permeability to dextran (paracellular leak). Permeability is normalized to control. Transcytosis was measured by ELISA as described in Materials and Methods; ${ }^{*} P<0.05$ for the effect of S1P on albumin permeability. Mean flux of dextran was $0.14 \pm 0.02 \times 10^{-6} \mathrm{~cm} / \mathrm{s}$ for control and $0.15 \pm 0.02 \times 10^{-6} \mathrm{~cm} / \mathrm{s}$ for S1P. Mean flux of albumin was $0.85 \pm 0.28 \times 10^{-7} \mathrm{~cm} / \mathrm{s}$ for control and $1.10 \pm 0.33 \times 10^{-7} \mathrm{~cm} / \mathrm{s}$ for S1P.

kocytes from the bloodstream to sites of infection. Nonetheless, it is now apparent that permeability of the endothelium to leukocytes and permeability to fluid and proteins are not necessarily synchronous. ${ }^{58,59}$ In fact, it is worth noting that the loss of fluid and proteins out of the vasculature during inflammation is far from benign. $3,60,61$ In acute lung injury, strategies that restrict fluid administration lead to improved lung function. ${ }^{61}$ In animal models of diseases characterized by disseminated microvascular permeability, such as sepsis and anaphylaxis, interventions that restore endothelial barrier integrity lead to improved blood pressure ${ }^{5}$ and increased survival. ${ }^{1,2}$ An understanding of how microvascular permeability is regulated is therefore essential for understanding inflammatory diseases and developing potential therapies.
Passage of fluid and proteins out of the vasculature can occur either between or through individual cells. Although both the paracellular and transcellular routes across the endothelium were described decades ago, ${ }^{62,63}$ remarkably little is known about the relationship between them. In particular, whether changes in one route can modulate the other is unknown. This paucity of literature about such a fundamental question in vascular biology stems in part from difficulties in measuring and quantifying transcytosis. Analyzing transcytosis and distinguishing it from paracellular leak has been challenging in vivo. Most studies have used electron microscopy of animal tissues, an arduous, expensive, and sometimes descriptive endeavor, although recent advances in intravital imaging appear promising. ${ }^{25,64}$ Dissecting out the molecular regulation of transcytosis and its link to paracellular leak would be more easily done in vitro; for instance, such a system would avoid the confounding effects of changes in blood pressure. ${ }^{27}$ However, there has been little analysis of in vitro transcytosis, partly because the density of caveolae decreases in cell culture ${ }^{22}$; furthermore, the frequency of transcellular events likely varies among different vascular beds and may be lowest in human umbilical vein endothelial cells, ${ }^{43}$ which are commonly used in cell culture experiments. To overcome this barrier, our laboratory devised two independent assays to

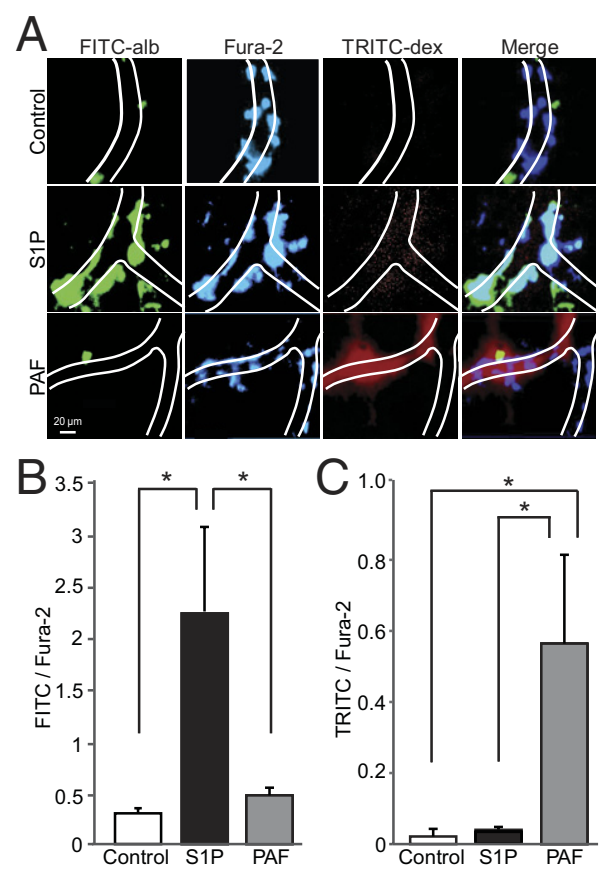

Figure 9. Reduction of paracellular leak by S1P causes induction of transcytosis in an ex vivo lung model. A: Isolated mouse lungs were perfused with Krebs-Henseleit buffer containing membrane-permeant fura-2 AM, FITCconjugated albumin (alb), and tetramethylrhodamine isothiocyanate (TRITC) dextran (dex) (molecular weight, approximately 70,000) in the presence or absence of either S1P $(1 \mu \mathrm{mol} / \mathrm{L})$ or platelet-activating factor (PAF; $50 \mathrm{nmol} /$ L). After 60 minutes, residual dyes were washed out and images were captured at the appropriate wavelength by intravital microscopy. B-C: The fluorescence intensity of FITC (B) and TRITC (C) was quantified in the vascular wall and surrounding parenchyma of lung venular capillaries and expressed relative to the respective fura-2 fluorescence. Images have been pseudo-colored for clarity. In each experiment, 10 to 15 single venular capillaries were viewed $\left(n=5\right.$ experiments per group; ${ }^{*} P<0.05$ ). 

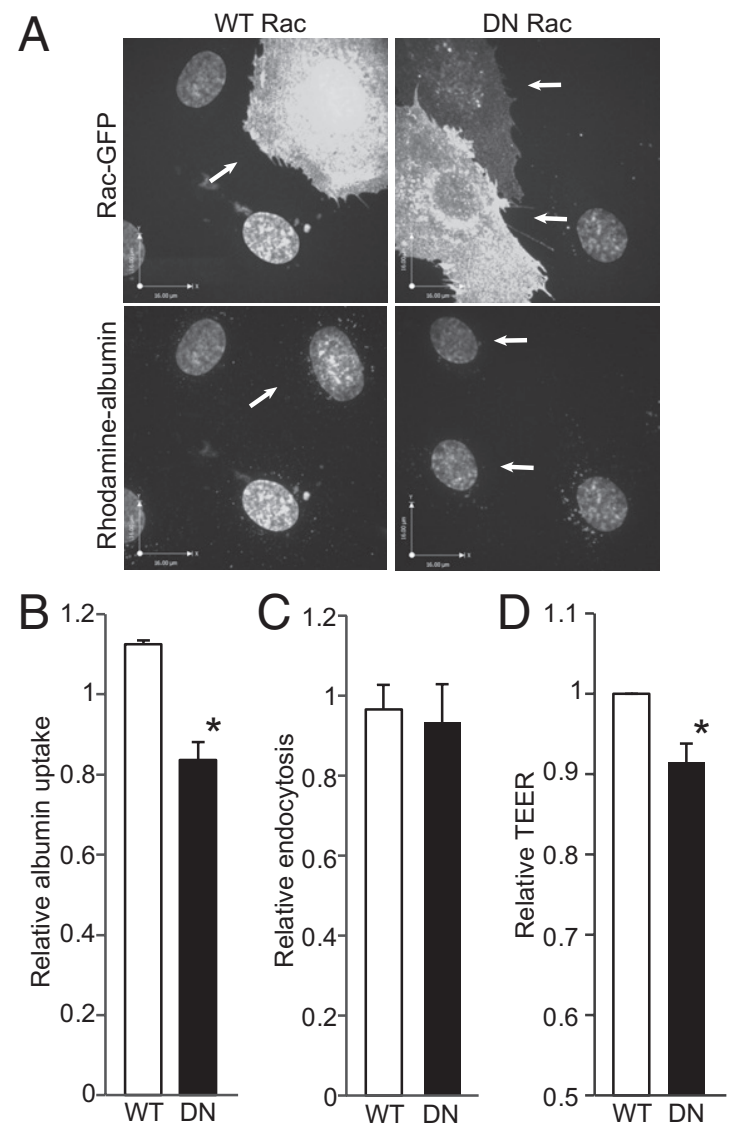

Figure 10. A: Inhibition of Rac inhibits albumin uptake. The internalization of membrane-bound rhodamine-conjugated albumin in endothelium transfected with WT- or DN-Rac-GFP was compared. Nuclei were stained with DAPI. Images are Z-stack projections. Arrows denote transfected cells. B: Fluorescence of endosomes was measured per cell and background fluorescence was subtracted. For both WT- and DN-Rac cells, measurements were normalized to untransfected cells. Measurements were taken of 95 transfected cells $\left(n=3 ;{ }^{*} P<0.05\right)$. C: The endocytosis of FM 4-64 is not affected by transfection with WT- or DN-Rac. The internalization of FM 4-64 in endothelium transfected with WT- or DN-Rac-GFP was compared. Quantitation of FM internalization was performed using ImageJ; measurements were taken of $>400$ cells and $>150$ transfected cells. D: Cells transfected with DN-Rac have a higher permeability than those transfected with WT-Rac. Equal numbers of transfected cells were seeded on transwells, and TEER was measured 24 hours later (mean \pm SD: WT, $26.3 \pm 1.5 \Omega \mathrm{cm}^{2}$; DN, $24.0 \pm 0.9$ $\left.\Omega \mathrm{cm}^{2}\right)\left({ }^{*} P<0.05\right)$

measure transcytosis by primary human microvascular endothelium. These experiments, complemented by electron microscopy, convincingly demonstrate that transcytosis can in fact be studied in vitro.

Using this as a starting point, we sought to determine how transcytosis and paracellular leak were related. A connection seemed plausible because tissue beds that are the most sensitive to inflammatory mediators, such as postcapillary venules, also display a high density of caveolae. ${ }^{65}$ Furthermore, signaling molecules that have been implicated in the generation of paracellular leak, such as Src kinase, are themselves essential for transcytosis. ${ }^{21,66}$ Lastly, given the critical nature of vascular integrity to homeostasis, there is a strong biological rationale for these two pathways to be co-regulated. Although ablation $^{26}$ or knockdown of caveolin- $1^{40}$ leads to inhibition of transcytosis, it has been controversial whether this results in increased paracellular leak or simply causes an alteration in capillary pressure or the glycocalyx. ${ }^{27}$ Furthermore, the pleiotropic effects of caveolin-1 make it difficult in such studies to attribute any change in permeability to the loss of transcytosis per se.

To answer this question, we inhibited transcytosis using different molecular and pharmacologic methods, each of which is well established to inhibit vesicular uptake. For instance, NEM is the prototypical inhibitor of SNARE function and has been used to inhibit vesicular traffic (including transcytosis) ${ }^{44}$ since the 1980s. ${ }^{67}$ Dynasore is a cell-permeable inhibitor of dynamin that has been extensively tested for specificity (and whose specificity was confirmed in our data). ${ }^{37}$ The K44A mutant of dynamin-2 has also been widely studied and is commonly used to block dynamin-dependent events. ${ }^{68} \mathrm{Fi}$ nally, the inhibition of vesicular uptake at temperatures $<15^{\circ} \mathrm{C}$ has been a feature of cell biological studies for decades. ${ }^{31,69}$ Remarkably, regardless of which of these methods was used to inhibit transcytosis, we observed an increase in paracellular leak. This was not simply due to the general inhibition of endocytosis because almost complete knockdown of clathrin by siRNA did not change the results. Furthermore, the increase in leak that we observed was not due to toxicity of the inhibitors or, in contrast to previous literature, due to depletion of caveolin- $1^{26}$ or increased nitric oxide synthase activity.

To determine the molecular mechanism of this relationship, we took advantage of the dynamin inhibitor Dynasore because its own mechanism of action is known and specific $^{37}$ (Figure 3). In addition, the acuity of its inhibition would allow us to distinguish the direct consequences of the loss of transcytosis from downstream compensatory events that might occur over time.

Our data demonstrate that the inhibition of transcytosis by blocking dynamin leads to a translocation of active Rac from the plasmalemma, culminating in the loss of cortical actin and the formation of intercellular gaps. Thus, the regulation of the localization of active Rac by dynamin forms the basis for a connection between transcytosis and paracellular leak. Such a relationship is plausible given the importance of Rac in the regulation of cortical actin, ${ }^{70}$ the fact that caveolae and the actin cytoskeleton are closely associated, ${ }^{71,72}$ and existing data describing the influence of dynamin on actin during endocytosis in general. ${ }^{48}$ The physiologic relevance of this observation is supported by the fact that the enhancement of paracellular integrity via the induction of Rac activity (by S1P) was sufficient to stimulate transcytosis. The fact that inhibition of Rac is sufficient to attenuate the internalization of membrane-bound albumin and to decrease endothelial resistance is also consistent with our model.

Our finding that Dynamin, Rac, and cortical actin constitute a critical link between paracellular leak and transcytosis is novel. Although cortical actin was previously thought to restrict the internalization of plasmalemmal vesicles, ${ }^{73,74}$ recent data suggest a more complex relationship. ${ }^{75,76}$ The role of Rac in regulating endocytosis is similarly nuanced; although activated Rac has been shown to inhibit clathrin-mediated endocytosis, ${ }^{77}$ it has 
also been reported to stimulate pinocytosis, ${ }^{70}$ which, like transcytosis of albumin, is clathrin independent. The abundance of signals that regulate Rac activity indicates that the balance between paracellular and transcellular leak has the potential to be dynamic and exquisitely responsive to cellular cues.

To our knowledge, this is the first demonstration of a reciprocal relationship between paracellular and transcellular permeability in resting endothelium. ${ }^{78}$ Previous literature has noted that some inflammatory stimuli can induce paracellular leak and up-regulate the number of caveolae or expression of caveolin-1, although most studies have not measured transcytosis itself. Furthermore, little mechanistic work has been performed to date. For instance, vascular endothelial growth factor and endotoxin are known to induce paracellular permeability ${ }^{13,16}$ while increasing caveolin-1 levels and/or the number of caveolae in endothelia. ${ }^{79,80}$ Similarly, leukotrienes have been reported to increase transcytosis ${ }^{64}$ but have also been demonstrated to induce the leakage of dextran, ${ }^{81}$ likely by paracellular means. Thus, whether induction of paracellular leak necessarily decreases transcytosis or whether, under certain conditions, both pathways can be induced is likely to depend on the specific inflammatory stimulus or the specific tissue bed. However, we obtained similar results in resting microvascular endothelium of both dermal and pulmonary origin.

It is important to acknowledge that in addition to endothelial cells, there are other determinants of vascular permeability, including nonendothelial cells, such as pericytes ${ }^{82}$ Compared with the importance of endothelial cells to barrier function, their contribution is less well defined. Similarly, although we observed a clear role for Rac, the GTPase RhoA is also known to contribute to vascular leak by inducing actin stress fibers. ${ }^{83}$ Although we did not observe any change in stress fibers on inhibition of transcytosis, further studies will be needed to definitively address the role of RhoA in the co-regulation of transcytosis and paracellular leak.

The resting permeability of our endothelial monolayers to dextran was similar or lower to that described in the literature, ${ }^{30,84}$ reflecting the health and integrity of the cells. Permeability to albumin, as measured during the biotin-BSA assay (Figure 1D), was lower than the permeability to albumin reported by others. ${ }^{84}$ This is likely because of the much higher molecular weight of biotinBSA compared with BSA alone, which significantly decreases passage across transwells. ${ }^{85}$

Although the occurrence of transcytosis is now widely accepted, its physiologic importance continues to be debated. ${ }^{19}$ In vitro models often neglect the contribution of convective transport that occurs when blood vessels are under pressure ${ }^{30}$; however, we obtained similar results under conditions incorporating transmural pressure. Furthermore, our ability to replicate our findings in an intact (ex vivo) lung is important validation of our model. Other investigators have reported that transcytosis is more prominent in vivo ${ }^{25}$ than in cell culture, which leads us to believe that the effects we observed will be proportionately more important in vivo as well.
In conclusion, we have demonstrated that transcytosis of albumin and paracellular leak are co-regulated in human endothelium. We hypothesize that such a relationship may allow for the fine regulation of total vascular permeability. For example, the ability to increase transcytosis at the expense of intercellular gap formation might be advantageous when blood vessels experience shear stress because it would theoretically decrease the risk of dissection of the vessel wall and, by shielding the underlying extracellular matrix, decrease the risk of intraluminal thrombus formation. We are currently investigating this notion. Finally, the identification of the specific molecular links between the two pathways of leak could have profound implications for the development of antiinflammatory therapies. For instance, if attempts to inhibit one pathway cause the enhancement of the other, the therapeutic benefit may be limited.

\section{References}

1. Camerer E, Regard JB, Cornelissen I, Srinivasan Y, Duong DN, Palmer D, Pham TH, Wong JS, Pappu R, Coughlin SR: Sphingosine1-phosphate in the plasma compartment regulates basal and inflammation-induced vascular leak in mice. J Clin Invest 2009, 119:1871-9

2. Kerschen EJ, Fernandez JA, Cooley BC, Yang XV, Sood R, Mosnier LO, Castellino FJ, Mackman N, Griffin JH, Weiler H: Endotoxemia and sepsis mortality reduction by non-anticoagulant activated protein C. J Exp Med 2007, 204:2439-48

3. Lee WL, Slutsky AS: Sepsis and endothelial permeability. N Engl J Med 2010, 363:689-91

4. Boyd JH, Forbes J, Nakada TA, Walley KR, Russell JA: Fluid resuscitation in septic shock: a positive fluid balance and elevated central venous pressure are associated with increased mortality. Crit Care Med 2011, 39:259-65

5. Ye X, Ding J, Zhou X, Chen G, Liu SF: Divergent roles of endothelial NF-kappaB in multiple organ injury and bacterial clearance in mouse models of sepsis. J Exp Med 2008, 205:1303-15

6. Fleck A, Raines G, Hawker F, Trotter J, Wallace PI, Ledingham IM, Calman KC: Increased vascular permeability: a major cause of hypoalbuminaemia in disease and injury. Lancet 1985, 1:781-4

7. Majno G, Palade GE: Studies on inflammation, 1: the effect of histamine and serotonin on vascular permeability: an electron microscopic study. J Biophys Biochem Cytol 1961, 11:571-605

8. Wu NZ, Baldwin AL: Transient venular permeability increase and endothelial gap formation induced by histamine. Am J Physiol 1992, 262: $\mathrm{H} 1238-47$

9. Mehta D, Malik AB: Signaling mechanisms regulating endothelial permeability. Physiol Rev 2006, 86:279-367

10. Menzies BE, Kourteva I: Staphylococcus aureus alpha-toxin induces apoptosis in endothelial cells. FEMS Immunol Med Microbiol 2000, 29:39-45

11. Xu J, Zhang X, Pelayo R, Monestier M, Ammollo CT, Semeraro F, Taylor FB, Esmon NL, Lupu F, Esmon CT: Extracellular histones are major mediators of death in sepsis. Nat Med 2009, 15:1318-21

12. Andriopoulou $P$, Navarro $P$, Zanetti A, Lampugnani MG, Dejana E: Histamine induces tyrosine phosphorylation of endothelial cell-to-cell adherens junctions. Arterioscler Thromb Vasc Biol 1999, 19:2286-97

13. Gavard J, Gutkind JS: VEGF controls endothelial-cell permeability by promoting the beta-arrestin-dependent endocytosis of VE-cadherin. Nat Cell Biol 2006, 8:1223-34

14. Maruo N, Morita I, Shirao M, Murota S: IL-6 increases endothelial permeability in vitro. Endocrinology 1992, 131:710-4

15. Whitehead KJ, Chan AC, Navankasattusas S, Koh W, London NR Ling J, Mayo AH, Drakos SG, Jones CA, Zhu W, Marchuk DA, Davis GE, Li DY: The cerebral cavernous malformation signaling pathway promotes vascular integrity via Rho GTPases. Nat Med 2009, 15: 177-84

16. Goldblum SE, Ding X, Brann TW, Campbell-Washington J: Bacterial lipopolysaccharide induces actin reorganization, intercellular gap for- 
mation, and endothelial barrier dysfunction in pulmonary vascular endothelial cells: concurrent F-actin depolymerization and new actin synthesis. J Cell Physiol 1993, 157:13-23

17. Birukova AA, Adyshev D, Gorshkov B, Bokoch GM, Birukov KG, Verin AD: GEF-H1 is involved in agonist-induced human pulmonary endothelial barrier dysfunction. Am J Physiol Lung Cell Mol Physiol 2006 , 290:L540-8

18. Tuma PL, Hubbard AL: Transcytosis: crossing cellular barriers. Physiol Rev 2003, 83:871-932

19. Predescu SA, Predescu DN, Malik AB: Molecular determinants of endothelial transcytosis and their role in endothelial permeability. Am J Physiol Lung Cell Mol Physiol 2007, 293:L823-42

20. Schubert W, Frank PG, Razani B, Park DS, Chow CW, Lisanti MP Caveolae-deficient endothelial cells show defects in the uptake and transport of albumin in vivo. J Biol Chem 2001, 276:48619-22

21. Tiruppathi C, Song W, Bergenfeldt M, Sass P, Malik AB: Gp60 Activation mediates albumin transcytosis in endothelial cells by tyrosine kinase-dependent pathway. J Biol Chem 1997, 272:25968-75

22. Schnitzer JE, Carley WW, Palade GE: Specific albumin binding to microvascular endothelium in culture. Am J Physiol Heart Circ Physiol 1988, 254:H425-37

23. Nabi IR, Le PU: Caveolae/raft-dependent endocytosis. J Cell Biol 2003, 161:673-7

24. Oh P, Mclntosh DP, Schnitzer JE: Dynamin at the neck of caveolae mediates their budding to form transport vesicles by GTP-driven fission from the plasma membrane of endothelium. J Cell Biol 1998, 141:101-14

25. Oh P, Borgstrom P, Witkiewicz H, Li Y, Borgstrom BJ, Chrastina A, Iwata K, Zinn KR, Baldwin R, Testa JE, Schnitzer JE: Live dynamic imaging of caveolae pumping targeted antibody rapidly and specifically across endothelium in the lung. Nature Biotechnol 2007, 25: 327-37

26. Schubert W, Frank PG, Woodman SE, Hyogo H, Cohen DE, Chow CW, Lisanti MP: Microvascular hyperpermeability in caveolin-1 (-/-) knock-out mice: treatment with a specific nitric-oxide synthase inhibitor, L-NAME, restores normal microvascular permeability in Cav-1 null mice. J Biol Chem 2002, 277:40091-8

27. Rosengren B-I, Rippe A, Rippe C, Venturoli D, Sward K, Rippe B: Transvascular protein transport in mice lacking endothelial caveolae. Am J Physiol Heart Circ Physiol 2006, 291:H1371-7

28. Quest AF, Gutierrez-Pajares JL, Torres VA: Caveolin-1: an ambiguous partner in cell signalling and cancer. J Cell Mol Med 2008, 12 : $1130-50$

29. Gillrie MR, Krishnegowda G, Lee K, Buret AG, Robbins SM, Looareesuwan S, Gowda DC, Ho M: Src-family kinase dependent disruption of endothelial barrier function by Plasmodium falciparum merozoite proteins. Blood 2007, 110:3426-35

30. DeMaio L, Tarbell JM, Scaduto RC, Jr., Gardner TW, Antonetti DA: A transmural pressure gradient induces mechanical and biological adaptive responses in endothelial cells. Am J Physiol Heart Circ Physiol 2004, 286:H731-41

31. Vida TA, Emr SD: A new vital stain for visualizing vacuolar membrane dynamics and endocytosis in yeast. J Cell Biol 1995, 128:779-92

32. London NR, Zhu W, Bozza FA, Smith MC, Greif DM, Sorensen LK, Chen L, Kaminoh Y, Chan AC, Passi SF, Day CW, Barnard DL, Zimmerman GA, Krasnow MA, Li DY: Targeting Robo4-dependent Slit signaling to survive the cytokine storm in sepsis and influenza. Sci Transl Med 2010, 23ra192:

33. Singleton PA, Salgia R, Moreno-Vinasco L, Moitra J, Sammani S, Mirzapoiazova T, Garcia JG: CD44 regulates hepatocyte growth factor-mediated vascular integrity: role of c-Met, Tiam1/Rac1, dynamin 2, and cortactin. J Biol Chem 2007, 282:30643-57

34. Jin JB, Bae H, Kim SJ, Jin YH, Goh CH, Kim DH, Lee YJ, Tse YC, Jiang L, Hwang I: The Arabidopsis dynamin-like proteins ADL1C and ADL1E play a critical role in mitochondrial morphogenesis. Plant Cell 2003, 15:2357-69

35. Flannagan RS, Harrison RE, Yip CM, Jaqaman K, Grinstein S: Dynamic macrophage "probing" is required for the efficient capture of phagocytic targets. J Cell Biol 2010, 191:1205-18

36. Yin J, Hoffmann J, Kaestle SM, Neye N, Wang L, Baeurle J, Liedtke W, Wu S, Kuppe H, Pries AR, Kuebler WM: Negative-feedback loop attenuates hydrostatic lung edema via a cGMP-dependent regulation of transient receptor potential vanilloid 4. Circ Res 2008, 102:966-74
37. Macia E, Ehrlich M, Massol R, Boucrot E, Brunner C, Kirchhausen T: Dynasore, a cell-permeable inhibitor of dynamin. Dev Cell 2006 , 10:839-50

38. Hosoya K, Kubo H, Natsume H, Sugibayashi K, Morimoto Y, Yamashita S: The structural barrier of absorptive mucosae: site difference of the permeability of fluorescein isothiocyanate-labelled dextran in rabbits. Biopharm Drug Dispos 1993, 14:685-95

39. Collard CD, Park KA, Montalto MC, Alapati S, Buras JA, Stahl GL, Colgan SP: Neutrophil-derived glutamate regulates vascular endothelial barrier function. J Biol Chem 2002, 277:14801-11

40. Miyawaki-Shimizu K, Predescu D, Shimizu J, Broman M, Predescu S, Malik AB: siRNA-induced caveolin-1 knockdown in mice increases lung vascular permeability via the junctional pathway. Am J Physiol Lung Cell Mol Physiol 2006, 290:L405-13

41. Balzac F, Avolio M, Degani S, Kaverina I, Torti M, Silengo L, Small JV Retta SF: E-cadherin endocytosis regulates the activity of Rap1: a traffic light GTPase at the crossroads between cadherin and integrin function. J Cell Sci 2005, 118:4765-83

42. Wilson DW, Wilcox CA, Flynn GC, Chen E, Kuang WJ, Henzel WJ, Block MR, Ullrich A, Rothman JE: A fusion protein required for vesicle-mediated transport in both mammalian cells and yeast. Nature 1989, 339:355-9

43. Carman CV, Sage PT, Sciuto TE, de la Fuente MA, Geha RS, Ochs HD, Dvorak HF, Dvorak AM, Springer TA: Transcellular diapedesis is initiated by invasive podosomes. Immunity 2007, 26:784-97

44. Predescu D, Horvat R, Predescu S, Palade GE: Transcytosis in the continuous endothelium of the myocardial microvasculature is inhibited by N-ethylmaleimide. Proc Natl Acad Sci U S A 1994, 91:3014-8

45. Watanabe M, Hitomi M, van der Wee K, Rothenberg F, Fisher SA Zucker R, Svoboda KK, Goldsmith EC, Heiskanen KM, Nieminen AL: The pros and cons of apoptosis assays for use in the study of cells, tissues, and organs. Microsc Microanal 2002, 8:375-91

46. Altschuler Y, Barbas SM, Terlecky LJ, Tang K, Hardy S, Mostov KE, Schmid SL: Redundant and distinct functions for dynamin-1 and dynamin-2 isoforms. J Cell Biol 1998, 143:1871-81

47. Descamps L, Dehouck MP, Torpier G, Cecchelli R: Receptor-mediated transcytosis of transferrin through blood-brain barrier endothelial cells. Am J Physiol 1996, 270:H1149-58

48. Orth JD, McNiven MA: Dynamin at the actin-membrane interface Curr Opin Cell Biol 2003, 15:31-9

49. Tarbell JM, Demaio L, Zaw MM: Effect of pressure on hydraulic conductivity of endothelial monolayers: role of endothelial cleft shear stress. J Appl Physiol 1999, 87:261-8

50. Fujiwara T, Oda K, Yokota S, Takatsuki A, Ikehara Y: Brefeldin A causes disassembly of the Golgi complex and accumulation of secretory proteins in the endoplasmic reticulum. J Biol Chem 1988, 263:18545-52

51. Ju H, Zou R, Venema VJ, Venema RC: Direct interaction of endothelial nitric-oxide synthase and caveolin-1 inhibits synthase activity. J Bio Chem 1997, 272:18522-5

52. Maniatis NA, Brovkovych V, Allen SE, John TA, Shajahan AN, Tiruppathi C, Vogel SM, Skidgel RA, Malik AB, Minshall RD: Novel mechanism of endothelial nitric oxide synthase activation mediated by caveolae internalization in endothelial cells. Circ Res 2006, 99:870-7

53. Schraufstatter IU, Trieu K, Sikora L, Sriramarao P, DiScipio R: Complement $\mathrm{C} 3 \mathrm{a}$ and $\mathrm{C5a}$ induce different signal transduction cascades in endothelial cells. J Immunol 2002, 169:2102-10

54. Furst R, Bubik MF, Bihari $P$, Mayer BA, Khandoga AG, Hoffmann F, Rehberg M, Krombach F, Zahler S, Vollmar AM: Atrial natriuretic peptide protects against histamine-induced endothelial barrier dysfunction in vivo. Mol Pharmacol 2008, 74:1-8

55. Schlunck G, Damke H, Kiosses WB, Rusk N, Symons MH, WatermanStorer CM, Schmid SL, Schwartz MA: Modulation of Rac localization and function by dynamin. Mol Biol Cell 2004, 15:256-67

56. Pelkmans L, Zerial M: Kinase-regulated quantal assemblies and kissand-run recycling of caveolae. Nature 2005, 436:128-33

57. Garcia JG, Liu F, Verin AD, Birukova A, Dechert MA, Gerthoffer WT, Bamberg JR, English D: Sphingosine 1-phosphate promotes endothelial cell barrier integrity by Edg-dependent cytoskeletal rearrangement. J Clin Invest 2001, 108:689-701

58. Phillipson M, Kaur J, Colarusso P, Ballantyne CM, Kubes P: Endothelial domes encapsulate adherent neutrophils and minimize increases in vascular permeability in paracellular and transcellular emigration. PLoS ONE 2008, 3:e1649 
59. DiStasi MR, Ley K: Opening the flood-gates: how neutrophil-endothelial interactions regulate permeability. Trends Immunol 2009, 30 547-56

60. Mangialardi RJ, Martin GS, Bernard GR, Wheeler AP, Christman BW, Dupont WD, Higgins SB, Swindell BB, Ibuprofen in Sepsis Study Group: Hypoproteinemia predicts acute respiratory distress syndrome development, weight gain, and death in patients with sepsis. Crit Care Med 2000, 28:3137-45

61. Wiedemann HP, Wheeler AP, Bernard GR, Thompson BT, Hayden D, deBoisblanc B, Connors AF, Jr., Hite RD, Harabin AL: Comparison of two fluid-management strategies in acute lung injury. N Engl J Med 2006, 354:2564-75

62. Predescu SA, Predescu DN, Palade GE: Plasmalemmal vesicles function as transcytotic carriers for small proteins in the continuous endothelium. Am J Physiol 1997, 272:H937-49

63. Nagy JA, Benjamin L, Zeng H, Dvorak AM, Dvorak HF: Vascular permeability, vascular hyperpermeability and angiogenesis. Angiogenesis 2008, 11:109-19

64. Moos MP, Mewburn JD, Kan FW, Ishii S, Abe M, Sakimura K, Noguch K, Shimizu T, Funk CD: Cysteinyl leukotriene 2 receptor-mediated vascular permeability via transendothelial vesicle transport. Faseb J 2008, 22:4352-62

65. Aird WC: Phenotypic heterogeneity of the endothelium, I: structure, function, and mechanisms. Circ Res 2007, 100:158-73

66. Shajahan AN, Timblin BK, Sandoval R, Tiruppathi C, Malik AB, Minshall RD: Role of Src-induced dynamin-2 phosphorylation in caveolae-mediated endocytosis in endothelial cells. J Biol Chem 2004, 279:20392-400

67. Diaz R, Mayorga LS, Weidman PJ, Rothman JE, Stahl PD: Vesicle fusion following receptor-mediated endocytosis requires a protein active in Golgi transport. Nature 1989, 339:398-400

68. Damke H, Binns DD, Ueda H, Schmid SL, Baba T: Dynamin GTPase domain mutants block endocytic vesicle formation at morphologically distinct stages. Mol Biol Cell 2001, 12:2578-89

69. lacopetta BJ, Morgan EH: The kinetics of transferrin endocytosis and iron uptake from transferrin in rabbit reticulocytes. J Biol Chem 1983 258:9108-15

70. Ridley AJ, Paterson HF, Johnston CL, Diekmann D, Hall A: The small GTP-binding protein rac regulates growth factor-induced membrane ruffling. Cell 1992, 70:401-10

71. Mundy DI, Machleidt T, Ying YS, Anderson RG, Bloom GS: Dual control of caveolar membrane traffic by microtubules and the actin cytoskeleton. J Cell Sci 2002, 115:4327-39

72. Millan J, Hewlett L, Glyn M, Toomre D, Clark P, Ridley AJ: Lymphocyte transcellular migration occurs through recruitment of endothelial ICAM-1 to caveola- and F-actin-rich domains. Nat Cell Biol 2006, 8:113-23
73. Qualmann B, Kelly RB: Syndapin isoforms participate in receptormediated endocytosis and actin organization. J Cell Biol 2000, 148 : 1047-62

74. Klein IK, Predescu DN, Sharma T, Knezevic I, Malik AB, Predescu S: Intersectin-2L regulates caveola endocytosis secondary to Cdc42mediated actin polymerization. J Biol Chem 2009, 284:25953-61

75. Stefan CJ, Padilla SM, Audhya A, Emr SD: The phosphoinositide phosphatase Sjl2 is recruited to cortical actin patches in the control of vesicle formation and fission during endocytosis. Mol Cell Biol 2005, 25:2910-23

76. Romer W, Pontani LL, Sorre B, Rentero C, Berland L, Chambon V, Lamaze C, Bassereau P, Sykes C, Gaus K, Johannes L: Actin dynamics drive membrane reorganization and scission in clathrin-independent endocytosis. Cell 2010, 140:540-53

77. Lamaze C, Chuang TH, Terlecky LJ, Bokoch GM, Schmid SL: Regulation of receptor-mediated endocytosis by Rho and Rac. Nature 1996, 382:177-9

78. Van Driessche W, Kreindler JL, Malik AB, Margulies S, Lewis SA, Kim $\mathrm{KJ}$ : Interrelations/cross talk between transcellular transport function and paracellular tight junctional properties in lung epithelial and endothelial barriers. Am J Physiol Lung Cell Mol Physiol 2007, 293: L520-4

79. Esser S, Wolburg K, Wolburg H, Breier G, Kurzchalia T, Risau W: Vascular endothelial growth factor induces endothelial fenestrations in vitro. J Cell Biol 1998, 140:947-59

80. Tiruppathi C, Shimizu J, Miyawaki-Shimizu K, Vogel SM, Bair AM, Minshall RD, Predescu D, Malik AB: Role of NF-kappaB-dependent caveolin-1 expression in the mechanism of increased endothelial permeability induced by lipopolysaccharide. J Biol Chem 2008, 283: 4210-8

81. Dunham B, Shepro D, Hechtman HB: Leukotriene induction of TxB2 in cultured bovine aortic endothelial cells. Inflammation 1984, 8:313-21

82. Armulik A, Genove G, Mae M, Nisancioglu MH, Wallgard E, Niaudet C, He L, Norlin J, Lindblom P, Strittmatter K, Johansson BR, Betsholtz C: Pericytes regulate the blood-brain barrier. Nature 2010, 468 557-61

83. Wojciak-Stothard B, Entwistle A, Garg R, Ridley AJ: Regulation of TNF-alpha-induced reorganization of the actin cytoskeleton and cellcell junctions by Rho, Rac, and Cdc42 in human endothelial cells. J Cell Physiol 1998, 176:150-65

84. Albelda SM, Sampson PM, Haselton FR, McNiff JM, Mueller SN, Williams SK, Fishman AP, Levine EM: Permeability characteristics of cultured endothelial cell monolayers. J Appl Physiol 1988, 64:308-22

85. Duffy SL, Murphy JT: Colorimetric assay to quantify macromolecule diffusion across endothelial monolayers. Biotechniques 2001, 31 : 495-6, 8, 500-1 